\title{
Improvement of the PR-CPA equation of state for modelling of acid gases solubilities in aqueous alkanolamine solutions
}

Wang, Tianyuan; El Ahmar, Elise; Coquelet, Christophe; Kontogeorgis, Georgios M.

\section{Published in:}

Fluid Phase Equilibria

Link to article, DOI:

10.1016/j.fluid.2018.04.019

Publication date:

2018

Document Version

Peer reviewed version

Link back to DTU Orbit

Citation (APA):

Wang, T., El Ahmar, E., Coquelet, C., \& Kontogeorgis, G. M. (2018). Improvement of the PR-CPA equation of state for modelling of acid gases solubilities in aqueous alkanolamine solutions. Fluid Phase Equilibria, 471, 7487. https://doi.org/10.1016/j.fluid.2018.04.019

\section{General rights}

Copyright and moral rights for the publications made accessible in the public portal are retained by the authors and/or other copyright owners and it is a condition of accessing publications that users recognise and abide by the legal requirements associated with these rights.

- Users may download and print one copy of any publication from the public portal for the purpose of private study or research.

- You may not further distribute the material or use it for any profit-making activity or commercial gain

- You may freely distribute the URL identifying the publication in the public portal 


\section{Accepted Manuscript}

Improvement of the PR-CPA equation of state for modelling of acid gases solubilities in aqueous alkanolamine solutions

Tianyuan Wang, Elise El Ahmar, Christophe Coquelet, Georgios M. Kontogeorgis

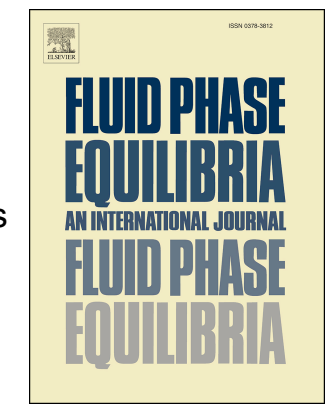

PII: S0378-3812(18)30166-3

DOI: 10.1016/j.fluid.2018.04.019

Reference: $\quad$ FLUID 11814

To appear in: $\quad$ Fluid Phase Equilibria

Received Date: 28 January 2018

Revised Date: 7 April 2018

Accepted Date: 17 April 2018

Please cite this article as: T. Wang, E. El Ahmar, C. Coquelet, G.M. Kontogeorgis, Improvement of the PR-CPA equation of state for modelling of acid gases solubilities in aqueous alkanolamine solutions, Fluid Phase Equilibria (2018), doi: 10.1016/j.fluid.2018.04.019.

This is a PDF file of an unedited manuscript that has been accepted for publication. As a service to our customers we are providing this early version of the manuscript. The manuscript will undergo copyediting, typesetting, and review of the resulting proof before it is published in its final form. Please note that during the production process errors may be discovered which could affect the content, and all legal disclaimers that apply to the journal pertain. 


\title{
Improvement of the PR-CPA equation of state for modelling of acid gases solubilities in aqueous alkanolamine solutions
}

\author{
Tianyuan Wang ${ }^{1,2}$, Elise El Ahmar ${ }^{1}$, Christophe Coquelet ${ }^{1}$ and Georgios M. Kontogeorgis ${ }^{2}$ \\ 1: Mines ParisTech-PSL Research University Centre of Thermodynamics of Processes CTP, 35 rue \\ Saint-Honore, 77305, Fontainebleau, France \\ 2: Center for Energy Resources Engineering (CERE), Department of Chemical and Biochemical \\ Engineering, Technical University of Denmark, DK-2800 Kgs. Lyngby, Denmark
}

\begin{abstract}
Chemical absorption with alkanolamines processes are commonly applied for natural gas purification. The knowledge of $\mathrm{CO}_{2}, \mathrm{H}_{2} \mathrm{~S}$, hydrocarbons and mercaptans solubilities in aqueous alkanolamine solutions is important in acid gas removal process simulation and design. In previous works, alkanes, aromatics and mercaptans solubilities in different aqueous alkanolamine solutions have been successfully represented by using the PR-CPA EoS. In this work, the PR-CPA EoS with a pseudo-chemical reaction approach is developed and applied to describe the solubility of acid gases in aqueous alkanolamines solutions. The results are in good agreement with a wide range of experimental data. Other relevant properties such as water content, electrolytes speciation and enthalpy of absorption are accurately predictd by PR-CPA EoS.
\end{abstract}

Keywords: CPA, acid gases, solubility, alkanolamine, natural gas 


\section{Introduction}

Among fossil fuels, natural gas is the cleanest, in terms of $\mathrm{CO}_{2}$ emission, burn efficiency and amount of air pollutant [1]. Methane is the prevailing element of natural gas; therefore, it contains other volatile molecules and a variety of impurities. In fact, it contains usually considerable amounts of acid gases $\left(\mathrm{CO}_{2}, \mathrm{H}_{2} \mathrm{~S}\right)$ which can lead to corrosion in equipment and pipelines if water is present. Mercaptans (mainly Methyl Mercaptan (MM) and Ethyl mercaptan (EM)) are known as toxic molecules with undesirable odour, and fuel combustion of mercaptans and other sulphur components can produce $\mathrm{SO}_{2}$ which is an undesirable chemical, and they can cause environmental issues. Acid gases and mercaptans are needed to be removed from natural gas until they reach acceptable standard. The treated natural gas contains a maximum of $2 \%$ of $\mathrm{CO}_{2}, 2-4 \mathrm{ppm}$ of $\mathrm{H}_{2} \mathrm{~S}$ and 5-30 ppm of total mercaptans [2]. Chemical absorption with alkanolamines [3] (such as monoethanolamine (MEA), diethanolamine (DEA), methyldiethanolamine (MDEA)) is the most well-established method to separate acid gas from natural gas. Acid gases react with alkanolamines in the absorber via acid-base chemical reactions to form electrolyte species. Mercaptans and hydrocarbons do not react with alkanolamines molecules, and they are physically absorbed by aqueous alkanolamine solutions. Thermodynamic models are of high importance for the design of the process, as they are linked directly to the accurate determination of the Vapor-Liquid Equilibrium and energy balances. Reliable thermodynamic models can allow designers not only to confirm their regulatory limits, but also to determine the best operation minimizing the loss of valuable hydrocarbons components. Our aim in this study is to develop an accurate thermodynamic model to describe alkane, aromatic and mercaptans solubilities (methane, ethane, propane, n-butane, n-pentane, n-hexane, benzene, toluene, MM, EM) in aqueous alkanolamine solutions, to estimate acid gases $\left(\mathrm{CO}_{2}, \mathrm{H}_{2} \mathrm{~S}\right)$ solubilities in aqueous alkanolamine solutions, and to estimate other crucial properties such as electrolytes concentration and vapor phase composition (mostly water content).

In previous works (Wang et al. [4, 5]), the PR-CPA EoS has been applied to describe the solubilities of hydrocarbons (including methane, ethane, propane, n-butane, n-pentane, n- 
hexane, benzene, toluene, and ethyl-benzene) and mercaptans (including methyl mercaptan and ethyl mercaptan) in aqueous MDEA, DEA and MEA solutions in Vapor Liquid Equilibrium (VLE), Liquid Liquid Equilibrium (LLE), and Vapor Liquid Liquid Equilibrium (VLLE) conditions. Parameters of associating compounds were determined by regression from experimental data. With optimized parameters, hydrocarbons and mercaptans solubilities in aqueous alkanolamine solutions were successfully represented by the model; the ARDs (Average relative deviation) are under $10 \%$ for alkanes, $18 \%$ for aromatics and $20 \%$ for mercaptans.

In this work, we focus on the solubility of acid gases in aqueous alkanolamines solutions. Unlike hydrocarbons, aromatics and mercaptans, the chemical reactions between $\mathrm{CO}_{2} /$ $\mathrm{H}_{2} \mathrm{~S}$ - alkanolamine - water and the formation of electrolyte species must be considered. The thermodynamic models used to resolve this problem can be grouped into three categories. The first and the simplest are the empirical models. Thanks to their simplicity, they are quite popular for early phase studies. These models utilize simple mathematical correlations for phase equilibria and fitted chemical equilibrium constants (Posey et al. [6]). The Kent-Eisenberg model [7] is an example of such a model. This kind of model is unsuitable for estimating the speciation and rigorous energy balances. More rigorous models can be divided into two categories: asymmetric approaches (excess Gibbs energy model for the liquid phase and EoS for the vapour phase) and symmetric approaches (equation of state-based models). For the asymmetric approach, the Desmukh-Mather model [8] has been widely used. This model utilizes the extended Debye-Hückel expression to estimate the activity coefficients of electrolyte species for long-range interactions. Dicko et al. [9] have applied this model for the modelling of equilibrium properties of $\mathrm{CO}_{2}-\mathrm{H}_{2} \mathrm{~S}$-MDEA-water system. This model uses empirical terms to represent short-range interactions. The electrolyte-NRTL [10] and UNIQUAC [11] models, which are rather more complex activity based models, can also be used. For the symmetric approach, the Fürst and Renon [12] EoS is one of the most widely used approaches. In this work, a new symmetric approach for accounting for the chemical reaction is developed and it is combined with the PR-CPA EoS. 


\section{Thermodynamic model}

Due to their simplicity, accuracy and computational efficiency, classical Cubic EoS are widely used in the petroleum and chemical industries. In the beginning of 1980 s, Wertheim [13] has developed a theory for chain and associating molecules. This theory is implemented in the Statistical Associating Fluid Theory EoS [14], which is based on perturbation theory and includes the hard sphere model as reference.

In 1996, Kontogeorgis et al. [15] have proposed to combine Wertheim's theory with an adapted radial distribution function and SRK EoS. This model is called Cubic Plus Association EoS (CPA EoS), expressed by Equation (1):

$$
\frac{A^{C P A}}{R T}=\frac{A^{\text {Cubic }}}{R T}+\frac{A^{A s s o c i a t i o n}}{R T}
$$

The cubic term can be any cubic EoS e.g. SRK or PR. As these two EoS are both widely used cubic EoS, and as a continuity of the previous work [16], the PR-CPA EoS has been applied in this work, expressed by Equation (2):

$$
P=\underbrace{\frac{R T}{v-b}-\frac{a(T)}{v(v+b)+b(v-b)}}_{\text {PR EoS }}-\frac{1 \frac{R T}{2}\left(1+\rho \frac{\partial \ln g_{r}}{\partial \rho}\right) \sum_{i} x_{i} \sum_{A_{i}}\left(1-X_{A_{i}}\right)}{\text { Wertheim term }}
$$

The CPA model is presented in detail in Appendix.

While the PR EoS accounts for the physical interaction contribution between the species, the association term takes into account the specific site-site interaction due to hydrogen bonding. Therefore, it is suitable for describing systems where water and alkanolamines molecules form hydrogen bonds (including self- and cross-interactions as well as solvation / induced association effects). Moreover, Dowell et al. [17] have successfully developed a simplified approach which allows treating chemical reactions with the Wertheim theory. In this approach, the chemical reactions between alkanolamine and $\mathrm{CO}_{2}$ have been treated as pseudo-cross association between them. 
Conventional configurations for alkanolamine and acid gas are not suitable to represent the chemical reaction between acid gas and alkanolamines. Nevertheless, Dowell et al. [17] have successfully represented the phase behaviour of $\mathrm{CO}_{2}$-water-MEA systems by using SAFT-VR [18] without any consideration of electrolytes species. They proposed that chemical reactions can be treated as strong associating physical interactions. Association sites that allow the pseudo-chemical reaction of $\mathrm{CO}_{2}$ and MEA are introduced in Weirtheim part of SAFT. This approach has been successfully applied with SAFT-VR to estimate $\mathrm{CO}_{2}$ solubility in MEA, MDEA, DEA, AMP, DEtA as multifunctional alkanolamine [17] [19], and some n-alkyl amines [20]. Recently, they applied this approach in process simulation and optimization for $\mathrm{CO}_{2}$ capture by aqueous solution of MEA [21]. Their approach for treating the chemical reactions is employed in this study. However, the solvation between $\mathrm{CO}_{2}$ and water was neglected in their work. But according to Tsivintzelis et al. [22], the solvation effect between $\mathrm{CO}_{2}$ and water should be considered for representing the $\mathrm{CO}_{2}$ - water binary system. The effect of considering the solvation effect between $\mathrm{CO}_{2}$ and water for describing the multicomponent $\mathrm{CO}_{2}$-alkanolamine-water system is investigated in this work, see supplementary information. The results shows the solvation effect gives better results, and it lead to less temperature dependent on $\mathrm{k}_{\mathrm{ij}}$. In this paper, results are obtained by considering the solvation effect. A new conception of association schemes for acid gas and alkanolamines is developed and investigated in this work, as can be seen in Figure 1.

\section{[FIGURE 1]}

Figure 1.a shows the association scheme for $\mathrm{CO}_{2}$, the e site is assigned as a solvation site which allows the cross association between $\mathrm{CO}_{2}$ and water, $\alpha_{1}$ and $\alpha_{2}$ are dedicated reaction sites which only react (cross-associate) with the electron site on alkanolamine. Depending on the nature of alkanolamine, $1 \alpha$ site can be activated for MDEA, and $2 \alpha$ sites are activated for MEA.

Figure 1.b is the association scheme for $\mathrm{H}_{2} \mathrm{~S}$, the two e sites are given as solvation sites which allows the cross association between $\mathrm{H}_{2} \mathrm{~S}$ and water, $\alpha_{1}$ and $\alpha_{2}$ are dedicated 
reaction sites which only react (cross-associate) with the electron site on alkanolamine. Depending on the nature of alkanolamine, the $\alpha_{1}$ site is activated for MDEA, and both $\alpha_{1}$ and $\alpha_{2}$ sites are activated for MEA.

Figure 1.c is the association scheme of water and also the symmetric model of alkanolamine. There are four sites in total including: two e sites and two $\mathrm{H}$ sites representing different functional groups. In this symmetric model, there is no distinction between e and $\mathrm{H}$ sites, i.e. the association behaviour of the different functional groups are identical.

Figure $1 . \mathrm{d}$ is the asymmetric model of alkanolamine, one $\mathrm{e}^{*}$ site is added based on the symmetric model of alkanolamine (4C) in order to distinguish the $-\mathrm{NH}$ from $-\mathrm{OH}$ functional groups ( $\mathrm{NH}$ group reacts with $\mathrm{CO}_{2}$ and $\mathrm{H}_{2} \mathrm{~S}$ ). In this asymmetric model, e* site on alkanolamine react only with the the $\alpha$ sites on acid gas.

The choice of symmetric model and asymmetric model for alkanolamine has been investigated. The asymmetric model has been finally chosen because it gives significantly better results than the symmetric one, and this fact has been proved by Dowell et al. [20]. As an example, the reaction between MEA and $\mathrm{CO}_{2}$ can be represented by Figure 2 .

\section{[FIGURE 2]}

Reaction products can be determined from a statistical analysis of the molecules notbonded at given sites, by using Equation (3) and (4):

$$
\begin{gathered}
{\left[\mathrm{MEACOO}^{-}\right]=\left[x_{\mathrm{CO} 2}\right]\left[\left(1-X^{\alpha 1, \mathrm{CO} 2}\right)\left(1-X^{\alpha 2, \mathrm{CO} 2}\right)\right]} \\
{\left[\mathrm{HCO}_{3}^{-1}\right]=\left[x_{\mathrm{CO} 2}\right]\left[X^{\alpha 1, \mathrm{CO} 2}+1-X^{\alpha 2, \mathrm{CO} 2}\right]}
\end{gathered}
$$

Where $x_{\mathrm{CO} 2}$ is the molar concentration of total $\mathrm{CO}_{2}$ in the liquid phase in equilibrium, it is related to the concentration of alkanolamine and loading ratio and $X^{\alpha i, C O 2}$ is the mole fraction of $\mathrm{CO}_{2}$ not bonded at $\alpha_{\mathrm{i}}$ site. 
For alkanolamine- acid gas mixtures, modified CR1 combining rules are applied, their cross-association volume $\beta^{A_{i} B_{j}}$ and the cross-association energy $\varepsilon^{A_{i} B_{j}}$ are fitted from VLE experimental data:

$$
\begin{aligned}
& \varepsilon^{A_{i} B_{j}}=\varepsilon^{\text {cross }}(\text { fitted }) \\
& \beta^{A_{i} B_{j}}=\beta^{\text {cross }}(\text { fitted })
\end{aligned}
$$

$k_{i j}$ is the binary interaction parameter in the van der Waals combining rule, and it is considered as an adjustable parameter. The influence of $k_{i j}$ and its temperature dependency will be studied in this work. $\varepsilon^{\text {cross }}, \beta^{\text {cross }}$,and $k_{i j}$ are considered as adjustable parameters, they are fitted simultaneously for acid gas-alkanolamine-water systems using ternary VLE data by minimizing objective function which is detailed in next the section.

\section{Model Parameterization}

\subsection{Pure component}

For self-associating components (water, MEA and MDEA), their parameters are taken from previous work (Wang et al. [4]). For acid gases, their parameters are calculated from critical properties and acentric factors, where the data are taken from NIST [23]. Pure component parameters used in this work are presented in Table 1.

\section{[TABLE 1]}

\subsection{Binary Interaction Parameters}

To the best of our knowledge, experimental data for the acid gas solubility in alkanolamine solutions are only available in the form of acid gas-water-alkanolamine ternary systems. Therefore, 3 BIPs (binary interaction parameters) listed in Table 2 are required to represent each acid gas-water-alkanolamine ternary systems. 
[Table 2]

\subsubsection{Acid gas-water Binary system}

Before investigating the solubility of acid gas in aqueous alkanolamine solution, the solubility of acid gas in pure water is studied by using the PR-CPA EoS. Rodriguez et al.[24] have neglected the solvation effects between $\mathrm{CO}_{2}$ and water with SAFT-VR when they consider $\mathrm{CO}_{2}$ solubility in different alkanolamine solutions. However, according to Tsivintzelis et al. [22], it is important to consider the solvation effect between $\mathrm{CO}_{2}$ and water in order to represent correctly $\mathrm{CO}_{2}$ - water binary systems (at least when the CPA equation of state is used). Therefore, the solvation between acid gases $\left(\mathrm{H}_{2} \mathrm{~S}\right.$ and $\left.\mathrm{CO} 2\right)$ withwater has been taken into account. $k_{i j}$ and two cross association parameters $\left(\varepsilon^{\mathrm{AiBj}}\right.$ and $\beta^{\mathrm{AiBj}}$ ) are included for such systems. $\varepsilon^{A i B j}$ is assumed to be a non-adjustable parameter using the experimental values proposed by Tsivintzelis et al. [22] [25]; 108.78 and 142.00 /bar.L.mol ${ }^{-1}$ for $\mathrm{H}_{2} \mathrm{~S}$-water and $\mathrm{CO}_{2}$-water respectively. In this work, $k_{i j}$ and $\beta^{A i B j}$ have been fitted to experimental data using the following objective function:

$$
f=100 \times \sum_{\mathrm{i}=1}^{\mathrm{n}}\left(\frac{\left|x_{1}^{c a l}-x_{1}^{\exp }\right|}{x_{1}^{\exp }}\right)_{\mathrm{i}}
$$

Table 3 summarizes the adjustable parameters and the ARD for the VLE data of acid gaswater binary systems; the ARDs for acid gas solubility in water are $2.1 \%$ and $5.4 \%$ for $\mathrm{H}_{2} \mathrm{~S}$-water and $\mathrm{CO}_{2}$-water binary systems respectively. Figure 3 shows the comparison between model results and the experimental data from Valtz et al. [26] for the $\mathrm{CO}_{2}-$ water binary system, while Figure 4 shows the comparison between PR-CPA results and the experimental data from Selleck et al. [27] for the $\mathrm{H}_{2} \mathrm{~S}$-water binary system.

[TABLE 3]

[FIGURE 3]

[FIGURE 4] 


\subsubsection{Acid gas-alkanolamine binary system}

In order to have the best model performance to represent acid gas solubility in alkanolamine solution, different model configurations considering the association scheme of alkanolamine, the influence of $k_{i j}$ between acid gas-alkanolamine and the solvation effect between acid gas-water have been investigated.

The $k_{i j}$ between acid gas-alkanolamine is assumed to be temperature dependent and is estimated from ternary acid gas-alkanolamine-water data as there is not relevant binary data. The difference between MEA and MDEA is that a second reaction forming carbamate should be considered in the case of MEA only. Therefore, the two $\alpha$ sites are both active in the MEA case, and two additional parameters $\beta^{A i B j}{ }_{\text {and }} \varepsilon^{A i B j}$ are involved in order to represent the formation of carbamate. There is a quantity of experimental data for acid-gas-water-alkanolamine ternary systems, the chosen experimental data in this work covers a wide range of temperature and a wide range of acid gas loading ratio.

The binary interaction parameters estimated from the experimental data are summarized in Table 4. The objective function used is given by Equation (8):

$$
f=100 \times \sum_{\mathrm{i}=1}^{\mathrm{n}}\left(\frac{\left|P^{\mathrm{cal}}-P^{\exp }\right|}{P^{\exp }}\right)_{\mathrm{i}}
$$

where $\mathrm{P}$ is the total pressure of acid gas-alkanolamine- $\mathrm{H}_{2} \mathrm{O}$ ternary systems.

[TABLE 4] 


\section{Results and discussion}

\subsection{Acid gas solubility in aqueous alkanolamine solutions}

\subsection{1 $\mathrm{CO}_{2}$-MEA-water ternary system}

Figure 5 shows the comparison between the total pressure of the $\mathrm{CO}_{2}$-MEA-water ternary system and the results obtained from PR-CPA with $30 \mathrm{wt} \%$ aqueous MEA solution. It can be highlighted that PR-CPA can accurately represent the total pressure of $\mathrm{CO}_{2}$-MEA-water ternary system in the temperature range from 298 to $398 \mathrm{~K}$, and $\mathrm{CO}_{2}$ loading ratio from 0 to 0.95 .

[FIGURE 5]

\subsection{2 $\mathrm{CO}_{2}$-MDEA-water ternary system}

Figure 6 and 7 show the results for the $\mathrm{CO}_{2}$-MDEA-water ternary systems for 32 and 19 wt \% MDEA aqueous solution respectively. PR-CPA shows excellent representation for the $\mathrm{CO}_{2}$ solubility in aqueous MDEA solutions in a wide range of temperature from 313 to $413 \mathrm{~K}$. Our model is more accurate than the Desmukh-Mather model with less parameter. The comparison between our model and Desmukh-Mather model is presented in supplementary information.

[FIGURE 6]

[FIGURE 7]

\subsection{3 $\quad \mathrm{H}_{2} \mathrm{~S}$-MEA-water ternary system}

Figure 8 shows the comparison between $\mathrm{H}_{2} \mathrm{~S}$ partial pressure for the $\mathrm{H}_{2} \mathrm{~S}$-MEA-water ternary system and the PR-CPA results with $30 \mathrm{wt} \%$ aqueous MEA solution. It can be seen that PR-CPA can accurately represent the $\mathrm{H}_{2} \mathrm{~S}$ partial pressure of the $\mathrm{H}_{2} \mathrm{~S}$-MEA- 
water ternary system within the temperature range from 298 to $393 \mathrm{~K}$, when the $\mathrm{H}_{2} \mathrm{~S}$ loading ratio is greater than 0.2. However, PR-CPA overestimates the $\mathrm{H}_{2} \mathrm{~S}$ partial pressure when the $\mathrm{H}_{2} \mathrm{~S}$ loading rate is low $(<0.2)$.

[FIGURE 8]

\subsection{4 $\mathrm{H}_{2} \mathrm{~S}$-MDEA-water ternary system}

Figure 9 and 10 show the comparison between the total pressure of $\mathrm{H}_{2} \mathrm{~S}-\mathrm{MDEA}$-water ternary system and the results from PR-CPA at different concentrations (20 and $48 \mathrm{wt} \%$ ). It can be seen that PR-CPA can accurately represent the total pressure of $\mathrm{H}_{2} \mathrm{~S}$-MDEAwater ternary system in the temperature range from 311 to $388 \mathrm{~K}$, and in the whole $\mathrm{H}_{2} \mathrm{~S}$ loading ratio from 0 to 0.988 .

[FIGURE 9]

[FIGURE 10]

\subsection{Model validation}

In this section, PR-CPA EoS developed will be validated by comparing exploration/prediction results with different type of experimental data not used in parameter estimation including acid gas solubility in aqueous alkanolamine solution, vapour phase composition, liquid phase speciation, enthalpy of absorption, and acid gas mixture solubilities.

\subsubsection{Acid gas solubility in aqueous alkanolamine solution}

Experimental data with $25 \mathrm{wt} \%$ MDEA aqueous solution [34] is used to validate the model extrapolation as this data were not used in parameter estimation. These data are at a temperature range of 298-348K, and the results are shown in Figure 11. It can be seen that the total pressure is correctly estimated by PR-CPA with an ARD about $12 \%$.

[FIGURE 11] 
For the $\mathrm{H}_{2} \mathrm{~S}$-MDEA-water ternary system, it can be seen in Figure 12 that, the tendency of total pressure is correctly estimated by PR-CPA with ARD of $17 \%$. However, the total pressure is overestimated for low $\mathrm{H}_{2} \mathrm{~S}$ loading ratio $(<0.2)$.

[FIGURE 12]

\subsubsection{Vapour phase concentration}

Accurate estimation of MEA concentration in the vapour phase is necessary in process design in order to estimate the amount of solvent loss. Moreover, the water content is crucial for the design of drying units. As the concentration of MDEA is very low in the vapour phase (about $10^{-6}$ in mole composition), there are no available experimental data for those systems. However, in this work we have chosen the $\mathrm{CO}_{2}-\mathrm{MEA}$-water ternary system for model validation. Figure 13 and 14 show that PR-CPA can satisfactorily estimate vapour phase composition for water and MEA at 333 and $313 \mathrm{~K}$.

[FIGURE 13]

[FIGURE 14]

\subsubsection{Liquid phase speciation}

Another important aspect in the model validation is the description of the degree of speciation of the system. For the $\mathrm{CO}_{2}$-MDEA-water, the main products of reactions in the model are the $\mathrm{MDEAH}^{+}$and $\mathrm{HCO}_{3}{ }^{-1}$. The concentration of these products can be obtained from the ratio of unbonded $\alpha$ sites on the $\mathrm{CO}_{2}$ as follows:

$$
\begin{gathered}
{\left[\mathrm{MDEA}^{+}\right]=\left[x_{\mathrm{CO} 2}\right]\left[\left(1-X^{\alpha 1, \mathrm{CO} 2}\right)\right]} \\
{\left[\mathrm{HCO}_{3}^{-1}\right]=\left[x_{\mathrm{CO} 2}\right]\left[X^{\alpha 1, \mathrm{CO} 2}\right]}
\end{gathered}
$$

where $\mathrm{x}_{\mathrm{CO} 2}$ is the molar concentration of total $\mathrm{CO}_{2}$ in the liquid phase in equilibrium. 
The analysis of the degree of speciation for $\mathrm{CO}_{2}-\mathrm{MDEA}-\mathrm{H}_{2} \mathrm{O}$ at $313 \mathrm{~K}$ is presented in Figure 15. PR-CPA EoS provides very good estimations of the composition in MDEA and bicarbonate at $313 \mathrm{~K}$.

\section{[FIGURE 15]}

For the $\mathrm{CO}_{2}$-MEA-water, the reaction mechanism is more complex, and the concentration of different electrolytes was calculated from the fraction of molecules of $\mathrm{CO}_{2}$ not bonded at the site $\alpha\left(\mathrm{X}^{\alpha, \mathrm{CO} 2}\right)$ by using equations ( 3 and 4$)$ :

The PR-CPA EoS can accurately predict the speciation of acid gas reacting with aqueous alkanolamine solutions. Figure 16 shows the excellent agreement between PR-CPA estimation and experimental data for the speciation for carbamate and bicarbonate for the $\mathrm{CO}_{2}$-MEA-water ternary system at $313 \mathrm{~K}$.

[FIGURE 16]

\subsubsection{Enthalpy of absorption}

In the context of acid gas removal processes, another important property to consider is the enthalpy of absorption of $\mathrm{CO}_{2}$, as the major source of heat in the system is the heat that is released when $\mathrm{CO}_{2}$ is absorbed by alkanolamine. The enthalpy of absorption is calculated by using the following equation:

$$
\Delta H_{a b s}=\left(\frac{d \ln (P)}{d 1 / T}\right)_{x}
$$

For MDEA, the heat of absorption is not greatly affected by pressure [40]. The comparison between the PR-CPA EoS estimations and the experimental data for the enthalpy of absorption of $\mathrm{CO}_{2}$ in MDEA is shown in Figure 17. At $20 \mathrm{wt} \%$ MDEA, and in the temperature range from 298 to $333 \mathrm{~K}$, which is a typical temperature range for $\mathrm{CO}_{2}$ absorbers, the PR-CPA EoS is able to accurately predict the enthalpy of absorption 
of $\mathrm{CO}_{2}$. The overall ARD is $14.5 \%$. However, the increase of $-\Delta \mathrm{H}_{\mathrm{abs}}$ with temperature is not correctly predicted with PR-CPA EoS.

\section{[FIGURE 17]}

For MEA, the enthalpy of absorption of $\mathrm{CO}_{2}$ in aqueous MEA is predicted by PR-CPA EoS at 313 and $393 \mathrm{~K}$, as shown in Figure 18 and 19 respectively. At $313 \mathrm{~K}$, which is a typical operational temperature in the absorber, it can be seen that the enthalpy of absorption is accurately predicted when the $\mathrm{CO}_{2}$ loading ratio is lower than 0.4 , ie. before the formation of carbamate. However, PR-CPA EoS underestimates the enthalpy of absorption by $49 \%$ when the carbamate is formed. At $393 \mathrm{~K}$, which is an operational temperature in the desorber, the enthalpy of absorption can be considered as the opposite value of enthalpy of desorption. The trend of enthalpy of absorption variation as function of $\mathrm{CO}_{2}$ loading ratio is correctly predicted. The value is, however, underestimated by 25 $\mathrm{kJ} / \mathrm{mol} \mathrm{CO} 2$ over the whole $\mathrm{CO}_{2}$ loading ratio. Brand [42] has investigated the enthalpy of absorption of $\mathrm{CO}_{2}$ in aqueous MEA solution with SAFT-VR EoS. These values of enthalpy of absorption are also underestimated by $50 \mathrm{~kJ} / \mathrm{mol} \mathrm{CO} 2$ using the SAFT-VR mode. Uyan et al. [43] and Wangler et al. [44] have obtained better results with ePCSAFT with explicit electrolyte and chemical reaction terms to predict the enthalpy of absorption. Adding ion species terms could lead to a better description of enthalpy, however the main objective of this work is to present acid gas-water-water systems with a minimum number of parameters. As a solution, they proposed to reduce the deviation by adding a constant which does not seem to be a very consistent approach.

[FIGURE 18]

[FIGURE 19]

\subsubsection{Mixtures of $\mathrm{CO}_{2}$ and $\mathrm{H}_{2} \mathrm{~S}$ in alkanolamine solutions}

$\mathrm{CO}_{2}$ and $\mathrm{H}_{2} \mathrm{~S}$ are usually both present in the natural gas reserves. It is important to have a reliable thermodynamic model which is able to accurately estimate partial pressures of $\mathrm{CO}_{2}$ and $\mathrm{H}_{2} \mathrm{~S}$ in aqueous alkanolamine solutions. With the parameters presented in previous sections (and summarized in Tables 4), PR-CPA estimations are compared with 
the experimental data of $\mathrm{CO}_{2}-\mathrm{H}_{2} \mathrm{~S}-\mathrm{H}_{2} \mathrm{O}-\mathrm{MEA}$ by Lee et al. [45] and $\mathrm{CO}_{2}-\mathrm{H}_{2} \mathrm{~S}-\mathrm{H}_{2} \mathrm{O}$ MDEA by Jou et al. [46]. The temperature range is from 311 to $393 \mathrm{~K}$. PR-CPA EoS is in very good agreement with the experimental data, both for MEA and MDEA, figures are shown in suppelementary information.

In the context of statistical error, we considered that for the parity graph, if adjustment is perfect, we have $Y_{\exp }=Y_{c a l}$. The hypothesis $\mathrm{H}_{0}$ for this study is the null hypothesis (no difference).

As the estimated value $Y_{\text {cal }}$ can be either larger or smaller than the experimental value $Y_{\text {exp }}$, two tailed students t-test [47] have been carried out for those systems, results are shown in Table 5. The $\mathrm{P}$ value is between 0.001 and 0.073 . P-values are computed based on the assumption that the null hypothesis is true. The obtained results lead to conclude that the PR-CPA EoS is able to well predict the acid gas mixture partial pressure for those two systems.

\section{Conclusion}

Following an approach previously proposed for SAFT-VR model, we have used PR-CPA EoS without explicitly accounting for the reactions for the modeling of $\mathrm{CO}_{2}$ and $\mathrm{H}_{2} \mathrm{~S}$ water-alkanolamine solutions. The reactions between acid gases and water are treated as strong associations by adding dedicated associations sites on water and acid gases. Adjustable parameters are obtained from some binary and ternary data and are in some cases temperature dependent. It can be concluded that PR-CPA EoS can accurately represent the solubility of acid gas in aqueous alkanolamine solutions over a wide range of conditions (temperatures and loadings). Less satisfactory results are obtained at high loadings. Furthermore, vapor phase compositions of importance to the estimation of solvent loss and the speciation in the liquid phase have been successfully predicted using the same adjustable parameters fitted to phase equilibria data. On the other hand, the 
estimation of enthalpy of absorption was only partially satisfactory, indicating that the temperature dependency of the model requires improvement. Finally, PR-CPA EoS has been further validated by correctly estimating multi-component systems containing acid gas mixture, alkanolamine, water, and methane.

In conclusion, PR-CPA EoS provides a convenient platform for performing calculations for mixtures with acid gases, water and alkanolamine with few adjustable parameters and without use of extensive experimental data. The PR-CPA EoS could be integrated into simulation software such as Prosim ${ }^{\circledR}$ or Aspen Plus ${ }^{\mathrm{TM}}$, in order to solve the challenges in process design in the context of acid gas treatment from natural gas.

One limitation is that as the reactions between acid gases and water have been neglected, the $\mathrm{pH}$ value of the loaded solvent cannot be calculated with present version of the model. A solution to this is to use an electrolyte equation of state e.g. by combining PR-CPA EoS with explicit electrolyte terms such as MSA or Debye Huckel and possibly adding a Born contribution as well. Such an approach is significantly more complex compared to the approach we proposed in this study. 


\section{Appendix The PR-CPA EoS}

$$
P=\frac{R T}{v-b}-\frac{a(T)}{v(v+b)+b(v-b)}-\frac{1}{2} \frac{R T}{v}\left(1+\rho \frac{\partial \ln g_{r}}{\partial \rho}\right) \sum_{i} x_{i} \sum_{A_{i}}\left(1-X_{A_{i}}\right)
$$

Where $v$ is the molar volume, $\mathrm{b}$ is the molar co volume parameter, $a(T)$ the temperature dependent energy parameter of the equation of state, $\rho$ the molar density $(\rho=1 / v), g_{r}$ the radial distribution function, and $X_{A i}$ is the fraction of sites $\mathrm{A}$ on molecule $\mathrm{i}$ (hence the subscript Ai) that do not form bonds with other hydrogen bonding sites. $X_{A i}$ is dependent on the association strength $\Delta^{A i B j}$ between association sites belonging to the different molecules. $X_{A i}$ is given as

$$
X_{A_{i}}=\frac{1}{1+\rho \sum_{j} x_{j} \sum_{B_{j}} X_{B_{j}} \Delta^{A_{i} B_{j}}}
$$

$X_{\mathrm{Bj}}$ is the fraction of sites $\mathrm{B}$ on molecule $\mathrm{j}$ that do not form hydrogen bonds with other association sites. The association strength $\triangle^{A i B j}$ is dependent on the radial distribution function $\mathrm{g}_{\mathrm{r}}$, the association energy $\varepsilon^{A i B j}$, and the association volume $\beta^{A i B j}$ between sites $\mathrm{A}_{\mathrm{i}}$ and $B_{j}$. The relation is given by equation:

$$
\Delta^{A_{i} B_{j}}=g_{r}\left[\exp \left(\frac{\varepsilon^{A_{i} B_{j}}}{R T}\right)-1\right] b_{i j} \beta^{A_{i} B_{j}}
$$

The equation for the radial distribution function is:

$$
g_{r}=\frac{1}{1-1.9 \eta}
$$

Where $\eta$ is the reduced fluid density given as:

$$
\eta=\frac{1}{4} b \rho
$$


and the co-volume parameter $\mathrm{b}$ is assumed to be temperature independent. 


\section{References}

[1] How much carbon dioxide is produced when different fuels are burned? - FAQ U.S. Energy Information Administration (EIA), (n.d.). https://www.eia.gov/tools/faqs/faq.cfm?id=73\&t=11 (accessed October 21, 2016).

[2] E. Huguet, B. Coq, R. Durand, C. Leroi, R. Cadours, V. Hulea, A highly efficient process for transforming methyl mercaptan into hydrocarbons and $\mathrm{H}_{2} \mathrm{~S}$ on solid acid catalysts, Appl. Catal. B Environ. 134-135 (2013) 344-348.

[3] A.L. Kohl, R.B. Nielsen, Chapter 2 - Alkanolamines for Hydrogen Sulfide and Carbon Dioxide Removal, in: Gas Purif. Fifth Ed., Gulf Professional Publishing, Houston, 1997: pp. 40-186. (accessed August 1, 2016).

[4] T. Wang, E. El Ahmar, C. Coquelet, Alkane solubilities in aqueous alkanolamine solutions with CPA EoS, Fluid Phase Equilibria. 434 (2017) 93-101. doi: 10.1016/j.fluid.2016.11.025.

[5] T. Wang, E. El Ahmar, C. Coquelet, S. Huang, Measurement and modeling of mercaptans solubility in aqueous alkanolamine solutions, GPA Midstream Conv. (2017).

[6] M.L. Posey, G.T. Rochelle, A Thermodynamic Model of Methyldiethanolamine- $\mathrm{CO}_{2}-\mathrm{H}_{2} \mathrm{~S}-$ Water, Ind. Eng. Chem. Res. 36 (1997) 39443953. doi:10.1021/ie970140q.

[7] R.L. Kent, B. Elsenberg, Better Data for Amine Treating., Hydrocarb. Process. 55 (1976) 87-90.

[8] R.D. Deshmukh, A.E. Mather, A mathematical model for equilibrium solubility of hydrogen sulfide and carbon dioxide in aqueous alkanolamine solutions, Chem. Eng. Sci. 36 (1981) 355-362. doi:10.1016/0009-2509(81)85015-4.

[9] M. Dicko, C. Coquelet, C. Jarne, S. Northrop, D. Richon, Acid gases partial pressures above a $50 \mathrm{wt} \%$ aqueous methyldiethanolamine solution: Experimental work and modeling, Fluid Phase Equilibria. 289 (2010) 99-109. doi: 10.1016/j.fluid.2009.11.012.

[10] C. -C. Chen, H.I. Britt, J.F. Boston, L.B. Evans, Local composition model for excess Gibbs energy of electrolyte systems. Part I: Single solvent, single completely dissociated electrolyte systems, AIChE J. 28 (1982) 588-596. doi:10.1002/aic.690280410.

[11] K. Thomsen, P. Rasmussen, Modeling of vapor-liquid-solid equilibrium in gasaqueous electrolyte systems, Chem. Eng. Sci. 54 (1999) 1787-1802. doi:10.1016/S0009-2509(99)00019-6.

[12] W. Fürst, H. Renon, Representation of excess properties of electrolyte solutions using a new equation of state, AIChE J. 39 (1993) 335-343. doi:10.1002/aic.690390213.

[13] M.S. Wertheim, Fluids with highly directional attractive forces. I. Statistical thermodynamics, J. Stat. Phys. 35 (1984) 19-34. doi:10.1007/BF01017362.

[14] W.G. Chapman, K.E. Gubbins, G. Jackson, M. Radosz, SAFT: Equation-of-state solution model for associating fluids, Fluid Phase Equilibria. 52 (1989) 31-38. doi:10.1016/0378-3812(89)80308-5. 
[15] G.M. Kontogeorgis, E.C. Voutsas, I.V. Yakoumis, D.P. Tassios, An Equation of State for Associating Fluids, Ind. Eng. Chem. Res. 35 (1996) 4310-4318. doi:10.1021/ie9600203.

[16] M. Hajiw, A. Chapoy, C. Coquelet, Hydrocarbons - water phase equilibria using the CPA equation of state with a group contribution method, Can. J. Chem. Eng. 93 (2015) 432-442. doi:10.1002/cjce.22093.

[17] N. Mac Dowell, F. Llovell, C.S. Adjiman, G. Jackson, A. Galindo, Modeling the Fluid Phase Behavior of Carbon Dioxide in Aqueous Solutions of Monoethanolamine Using Transferable Parameters with the SAFT-VR Approach, Ind. Eng. Chem. Res. 49 (2010) 1883-1899. doi:10.1021/ie901014t.

[18] A. Gil-Villegas, A. Galindo, P.J. Whitehead, S.J. Mills, G. Jackson, A.N. Burgess, Statistical associating fluid theory for chain molecules with attractive potentials of variable range, J. Chem. Phys. 106 (1997) 4168-4186. doi:10.1063/1.473101.

[19] C.V. Brand, J. Rodríguez, A. Galindo, G. Jackson, C.S. Adjiman, Validation of an absorber model of carbon dioxide capture in an aqueous amine solvent developed based on the SAFT-VR framework, in: I.A.K. and R. Srinivasan (Ed.), Comput. Aided Chem. Eng., Elsevier, 2012: pp. 930-934. doi:10.1016/B978-0-444-595065.50017-1.

[20] N. Mac Dowell, F.E. Pereira, F. Llovell, F.J. Blas, C.S. Adjiman, G. Jackson, A. Galindo, Transferable SAFT-VR Models for the Calculation of the Fluid Phase Equilibria in Reactive Mixtures of Carbon Dioxide, Water, and n-Alkylamines in the Context of Carbon Capture, J. Phys. Chem. B. 115 (2011) 8155-8168. doi:10.1021/jp107467s.

[21] C.V. Brand, E. Graham, J. Rodríguez, A. Galindo, G. Jackson, C.S. Adjiman, On the use of molecular-based thermodynamic models to assess the performance of solvents for $\mathrm{CO}_{2}$ capture processes: monoethanolamine solutions, Faraday Discuss. 192 (2016) 337-390. doi:10.1039/C6FD00041J.

[22] I. Tsivintzelis, G.M. Kontogeorgis, M.L. Michelsen, E.H. Stenby, Modeling phase equilibria for acid gas mixtures using the CPA equation of state. Part II: Binary mixtures with $\mathrm{CO}_{2}$, Fluid Phase Equilibria. 306 (2011) 38-56. doi: 10.1016/j.fluid.2011.02.006.

[23] Frenkel, M.; Chirico, R. D.; Diky, V. V.; Yan, X.; Dong, Q.; Muzny,, C., NIST ThermoData Engine, NIST Standard Reference Database 103, Version 1.0; National Institute of Standards and Technology, Standard Reference Data Program: Gaithersburg, MD, 2004., (n.d.).

[24] J. Rodriguez, N.M. Dowell, F. Llovell, C.S. Adjiman, G. Jackson, A. Galindo, Modelling the fluid phase behaviour of aqueous mixtures of multifunctional alkanolamines and carbon dioxide using transferable parameters with the SAFT-VR approach, Mol. Phys. 110 (2012) 1325-1348. doi:10.1080/00268976.2012.665504.

[25] I. Tsivintzelis, G.M. Kontogeorgis, M.L. Michelsen, E.H. Stenby, Modeling phase equilibria for acid gas mixtures using the CPA equation of state. I. Mixtures with H2S, AIChE J. 56 (2010) 2965-2982. doi:10.1002/aic.12207.

[26] A. Valtz, A. Chapoy, C. Coquelet, P. Paricaud, D. Richon, Vapour-liquid equilibria in the carbon dioxide-water system, measurement and modelling from 278.2 to 318.2 K, Fluid Phase Equilibria. 226 (2004) 333-344. doi: 10.1016/j.fluid.2004.10.013. 
[27] F.T. Selleck, L.T. Carmichael, B.H. Sage, Phase Behavior in the Hydrogen SulfideWater System, Ind. Eng. Chem. 44 (1952) 2219-2226. doi:10.1021/ie50513a064.

[28] J.I. Lee, A.E. Mather, Solubility of Hydrogen Sulfide in Water. Ber. Bunsen-Ges, Physical, 1977.

[29] F. Lucile, P. Cézac, F. Contamine, J.-P. Serin, D. Houssin, P. Arpentinier, Solubility of Carbon Dioxide in Water and Aqueous Solution Containing Sodium Hydroxide at Temperatures from (293.15 to 393.15) $\mathrm{K}$ and Pressure up to $5 \mathrm{MPa}$ : Experimental Measurements, J. Chem. Eng. Data. 57 (2012) 784-789. doi:10.1021/je200991x.

[30] L.W. Diamond, N.N. Akinfiev, Solubility of $\mathrm{CO}_{2}$ in water from -1.5 to $100{ }^{\circ} \mathrm{C}$ and from 0.1 to $100 \mathrm{MPa}$ : evaluation of literature data and thermodynamic modelling, Fluid Phase Equilibria. 208 (2003) 265-290. doi:10.1016/S0378-3812(03)00041-4.

[31] F.-Y. Jou, A.E. Mather, F.D. Otto, The solubility of $\mathrm{CO}_{2}$ in a 30 mass percent monoethanolamine solution, Can. J. Chem. Eng. 73 (1995) 140-147. doi:10.1002/cjce.5450730116.

[32] G. Kuranov, B. Rumpf, N.A. Smirnova, G. Maurer, Solubility of Single Gases Carbon Dioxide and Hydrogen Sulfide in Aqueous Solutions of NMethyldiethanolamine in the Temperature Range 313-413 K at Pressures up to 5 MPa, Ind. Eng. Chem. Res. 35 (1996) 1959-1966. doi:10.1021/ie950538r.

[33] J.I. Lee, F.D. Otto, A.E. Mather, The solubility of $\mathrm{H}_{2} \mathrm{~S}$ and $\mathrm{CO}_{2}$ in aqueous monoethanolamine solutions, Can. J. Chem. Eng. 52 (1974) 803-805. doi:10.1002/cjce.5450520617.

[34] R. Sidi-Boumedine, S. Horstmann, K. Fischer, E. Provost, W. Fürst, J. Gmehling, Experimental determination of carbon dioxide solubility data in aqueous alkanolamine solutions, Fluid Phase Equilibria. 218 (2004) 85-94. doi: 10.1016/j.fluid.2003.11.014.

[35] A.M. Bhairi, Experimental Equilibrium Between Acid Gases and Ethanolamine Solutions, (1984). https://shareok.org/handle/11244/18756 (accessed May 16, 2017).

[36] F.-Y. Jou, J.J. Carroll, A.E. Mather, F.D. Otto, The solubility of carbon dioxide and hydrogen sulfide in a $35 \mathrm{wt} \%$ aqueous solution of methyldiethanolamine, Can. J. Chem. Eng. 71 (1993) 264-268. doi:10.1002/cjce.5450710213.

[37] M.D. Hilliard, A predictive thermodynamic model for an aqueous blend of potassium carbonate, piperazine, and monoethanolamine for carbon dioxide capture from flue gas, Thesis, 2008. https://repositories.lib.utexas.edu/handle/2152/3900 (accessed June 21, 2017).

[38] J.P. Jakobsen, J. Krane, H.F. Svendsen, Liquid-Phase Composition Determination in $\mathrm{CO}_{2}-\mathrm{H}_{2} \mathrm{O}-$ Alkanolamine Systems: An NMR Study, Ind. Eng. Chem. Res. 44 (2005) 9894-9903. doi:10.1021/ie048813+.

[39] W. Böttinger, M. Maiwald, H. Hasse, Online NMR spectroscopic study of species distribution in MEA- $\mathrm{H}_{2} \mathrm{O}-\mathrm{CO}_{2}$ and DEA- $\mathrm{H}_{2} \mathrm{O}-\mathrm{CO}_{2}$, Fluid Phase Equilibria. 263 (2008) 131-143. doi: 10.1016/j.fluid.2007.09.017.

[40] Y.E. Kim, J.A. Lim, S.K. Jeong, Y.I. Yoon, S.T. Bae, S.C. Nam, Comparison of Carbon Dioxide Absorption in Aqueous MEA, DEA, TEA, and AMP Solutions, Bull. Korean Chem. Soc. 34 (2013) 783-787. doi:10.5012/bkcs.2013.34.3.783.

[41] M. Gupta, E.F. da Silva, A. Hartono, H.F. Svendsen, Theoretical study of differential enthalpy of absorption of $\mathrm{CO}_{2}$ with MEA and MDEA as a function of temperature, J. Phys. Chem. B. 117 (2013) 9457-9468. doi:10.1021/jp404356e. 
[42] C. Brand, $\mathrm{CO}_{2}$ capture using monoethanolamine solutions: development and validation of a process model based on the SAFT-VR equation of state, (2013). http://spiral.imperial.ac.uk/handle/10044/1/18081 (accessed July 5, 2017).

[43] M. Uyan, G. Sieder, T. Ingram, C. Held, Predicting CO2 solubility in aqueous Nmethyldiethanolamine solutions with ePC-SAFT, Fluid Phase Equilibria. 393 (2015) 91-100. doi: 10.1016/j.fluid.2015.02.026.

[44] A. Wangler, G. Sieder, T. Ingram, M. Heilig, C. Held, Prediction of CO2 and H2S solubility and enthalpy of absorption in reacting N-methyldiethanolamine /water systems with ePC-SAFT, Fluid Phase Equilibria. 461 (2018) 15-27. doi: 10.1016/j.fluid.2017.12.033.

[45] Solubility of hydrogen sulfide in aqueous mixtures of monoethanolamine with $\mathrm{N}$ methyldiethanolamine, (n.d.). http://pubs.acs.org/doi/pdf/10.1021/je00009a025 (accessed September 20, 2017).

[46] F.-Y. Jou, F.D. Otto, A.E. Mather, The solubility of mixtures of $\mathrm{H}_{2} \mathrm{~S}$ and $\mathrm{CO}_{2}$ in an mdea solution, Can. J. Chem. Eng. 75 (1997) 1138-1141. doi:10.1002/cjce.5450750618.

[47] The Probable Error of a Mean, Biometrika. 6 (1908) 1-25. doi:10.1093/biomet/6.1.1. 


\section{List of figures}

Figure 1 association schemes developed in this research a) $\mathrm{CO}_{2}$, b) $\mathrm{H}_{2} \mathrm{~S}$, c) water and symmetric model for alkanolamine, d) asymmetric model for alkanolamine.

Figure 2 Reaction mechanism between $\mathrm{CO}_{2}$ and MEA (asymmetric model).

Figure 3 Comparison of experimental $\mathrm{CO}_{2}$ solubility in water and PR-CPA EoS results, solid line: PR-CPA EoS symbols: experimental data from Valtz et al. [26] ; (0)=298 K, $(\square)=308 \mathrm{~K},(*)=318 \mathrm{~K}$.

Figure 4 Comparison of experimental $\mathrm{H}_{2} \mathrm{~S}$ solubility in water and PR-CPA results, symbols: experimental data from Selleck et al. [27]; solid lines: PR-CPA EoS, $(\square)=311 \mathrm{~K}$ $(\mathrm{x})=344 \mathrm{~K},(\mathrm{O})=377 \mathrm{~K}$.

Figure 5 Comparison of experimental total pressure of $\mathrm{CO}_{2}-\mathrm{MEA}$-water ternary system with 30 wt\% MEA and PR-CPA results. Solid lines: PR-CPA EoS. Symbols: experimental data from Jou et al. [31]. ( $\Delta)=298 \mathrm{~K},(\bullet)=333 \mathrm{~K}, \quad(\times)=353 \mathrm{~K},(+)=393 \mathrm{~K}$ Figure 6 Comparison of experimental total pressure of $\mathrm{CO}_{2}$-MDEA-water ternary system with $32 \mathrm{wt} \%$ MDEA and PR-CPA results. Solid lines: PR-CPA EoS. Symbols: experimental data [32]. $(\diamond)=313 \mathrm{~K},(\boldsymbol{\Delta})=333 \mathrm{~K},(\boldsymbol{\bullet})=373 \mathrm{~K},(\bullet)=393 \mathrm{~K},(\times)=413 \mathrm{~K}$. Figure 7 Comparison of experimental total pressure of $\mathrm{CO}_{2}$-MDEA-water ternary system with 19 wt\% MDEA and PR-CPA results. Solid lines: PR-CPA EoS. Symbols: experimental data Kuranov et al. [32]. $(\bullet)=313 \mathrm{~K},(\boldsymbol{\Delta})=333 \mathrm{~K},(\bullet)=373 \mathrm{~K},(\bullet)=393 \mathrm{~K}$, $(\times)=413 \mathrm{~K}$

Figure 8 Comparison of experimental $\mathrm{H}_{2} \mathrm{~S}$ partial pressure of $\mathrm{H}_{2} \mathrm{~S}$-MEA-water ternary system with $30 \mathrm{wt} \%$ MEA and PR-CPA results. Solid lines: PR-CPA EoS, symbols: experimental data from Lee et al. [33]. $(\bullet)=298 \mathrm{~K},(\boldsymbol{\Delta})=313 \mathrm{~K},(\boldsymbol{\bullet})=333 \mathrm{~K},(\bullet)=353 \mathrm{~K}$, $(\times)=373 \mathrm{~K},(+)=393 \mathrm{~K}$.

Figure 9 Comparison of experimental total pressure of $\mathrm{H}_{2} \mathrm{~S}$-MDEA-water ternary system with 48 wt\% MDEA and PR-CPA results. Solid lines: PR-CPA EoS. Symbols: experimental data from Sidi-Boumedine et al. [34] . ( $)=313 \mathrm{~K},(\boldsymbol{\bullet})=373 \mathrm{~K}$.

Figure 10 Comparison of experimental total pressure of $\mathrm{H}_{2} \mathrm{~S}$-MDEA-water ternary system with 20 wt\% MDEA and PR-CPA results. Solid lines: PR-CPA EoS. Symbols: experimental data from Bhairi et al. [35] . $(\diamond)=311 \mathrm{~K},(\boldsymbol{\Delta})=338 \mathrm{~K},(\boldsymbol{\bullet})=388 \mathrm{~K}$.

Figure 11 Exploration of total pressure of $\mathrm{CO}_{2}$-MDEA-water ternary system with $25 \mathrm{wt} \%$ MDEA using PR-CPA. Solid lines: PR-CPA EoS. Symbols: experimental data from SidiBoumedine et al.[34]. $(\diamond)=298 \mathrm{~K},(\boldsymbol{\Delta})=313 \mathrm{~K},(\boldsymbol{\bullet})=348 \mathrm{~K}$.

Figure 12 Exploration of total pressure of the $\mathrm{H}_{2} \mathrm{~S}$-MDEA-water ternary system with 35 wt\% MDEA using PR-CPA. Symbols: experimental data from Jou et al. [36] . Solid lines: PR-CPA EoS. $(\bullet)=313 \mathrm{~K},(\boldsymbol{\Delta})=373 \mathrm{~K}$. 
Figure 13 Comparaison of vapour phase composition of the $\mathrm{CO}_{2}$-MEA-water ternary system with $30 \mathrm{wt} \% \mathrm{MEA}$ at $333.15 \mathrm{~K}$ using PR-CPA. Lines: PR-CPA estimations, Solid line: $\mathrm{y}_{\mathrm{wate}}$, dashed line: $\mathrm{y}_{\mathrm{MEA}}$, symbol: experimental data from Hilliard et al. [37] $(\boldsymbol{\Delta})=\mathrm{y}_{\text {water }},(\diamond)=$ y $_{\text {MEA. }}$.

Figure 14 Comparaison of vapour phase composition of $\mathrm{CO}_{2}$-MEA-water ternary system with $30 \mathrm{wt} \% \mathrm{MEA}$ at $313.15 \mathrm{~K}$ using PR-CPA. Lines: PR-CPA estimations, Solid line: $\mathrm{y}_{\text {water }}$, dashed line: $\mathrm{y}_{\text {MEA }}$, symbol: experimental data from Hilliard et al. [37] $(\boldsymbol{\Delta})=\mathrm{y}_{\text {water }},($ $\diamond)=\mathrm{y}_{\mathrm{MEA}}$

Figure 15 Prediction of liquid phase electrolyte speciation of $\mathrm{CO}_{2}$-MDEA-water ternary system with 30 wt \% MDEA at 313K using PR-CPA. Solid line: MDEA, dotted line: $\mathrm{HCO}_{3}{ }^{-1}$ symbols: experimental data from Jakobsen et al. [38]: $(\Delta)=\mathrm{HCO}_{3}{ }^{-1},(0)=\mathrm{MDEA}$.

Figure 16 Prediction of liquid phase electrolyte speciation of $\mathrm{CO}_{2}-\mathrm{MEA}$-water ternary system with $30 \mathrm{wt} \% \mathrm{MEA}$ at $313.15 \mathrm{~K}$ using PR-CPA. Solid line: $\mathrm{HCO}_{3}{ }^{-1}$, dashed line: $\mathrm{MEACOO}^{-}$, dotted line: $\mathrm{MEA}+\mathrm{MEAH}^{+}$, symbols: experimental data from Hilliard et al. [39] $(\Delta)=\mathrm{HCO}_{3}^{-1},(\diamond)=\mathrm{MEACOO}^{-}(\circ)=\mathrm{MEA}+\mathrm{MEAH}^{+}$from Hilliard [37], $(\boldsymbol{\Delta})=\mathrm{HCO}_{3}{ }^{-}$ ${ }^{1},(\diamond)=$ MEACOO $_{-}(\bullet)=M E A+M^{\prime}$ MH $^{+}$.

Figure 17 Prediction of enthalpy of absorption of $\mathrm{CO}_{2}$-MDEA-water ternary system with $20 \mathrm{wt} \%$ MDEA loading ratio 0.5 using PR-CPA EoS. Lines: PR-CPA EoS prediction, symbols: experimental data from Gupta et al. [41]

Figure 18 Prediction of enthalpy of absorption of $\mathrm{CO}_{2}$-MEA-water ternary system with 30 wt \% MEA at $313.15 \mathrm{~K}$ using PR-CPA. Solid line PR-CPA EoS, symbol: experimental data from Hilliard et al. [37]

Figure 19 Prediction of enthalpy of absorption of $\mathrm{CO}_{2}$-MEA-water ternary system with 30 wt \% MEA at $393.15 \mathrm{~K}$ using PR-CPA. Solid line: PR-CPA EoS, symbols: experimental data from Hilliard et al. [37]. 


\section{List of tables}

Table 1. PR-CPA EoS parameters for compounds for association compounds considered in this work .

Table 2 Overview of BIPs required representing alkane-water-alkanolamine ternary systems.

Table 3. BIP values and ARD of liquid compositions $\left(\mathrm{x}_{\text {acid gas }}\right)$ between PR-CPA EoS results and experimental data for $\mathrm{CO}_{2}$-water binary system.

Table 4 BIP values and ARD of total pressure between PR-CPA EoS results and experimental data for acid gas -alkanolamine binary system

Table 5 Student test results for acid gas mixture in aqueous alkanolamine solution 
Table 1. PR-CPA EoS parameters for compounds for association compounds considered in this work .

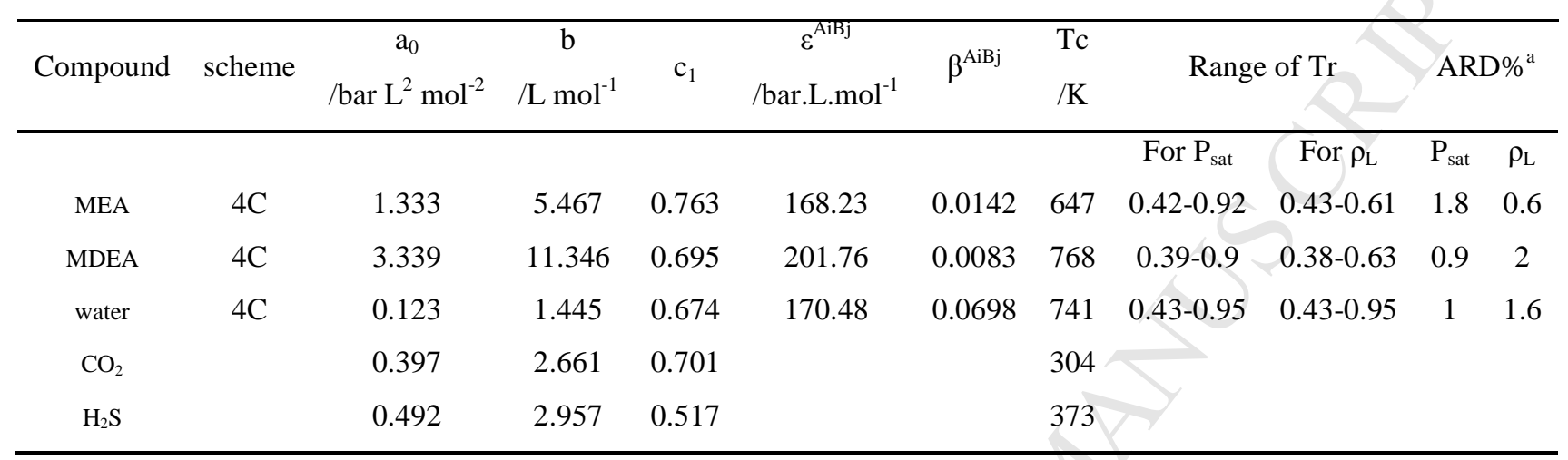

${ }^{\mathrm{a}} \mathrm{ARD} \%=1 / \mathrm{np} \times \Sigma\left|1-\chi_{i}^{\mathrm{calc}} / \chi_{i}^{\mathrm{exp}}\right| \times 100 \% \cdot \chi: \mathrm{P}_{\mathrm{sat}}$ or $\rho_{\mathrm{L}}$ 
Table 2 Overview of BIPs required representing alkane-water-alkanolamine ternary systems.

\begin{tabular}{c|ccc}
\hline & Alkanolamine & Water & Acid gas \\
\hline Alkanolamine & NA & Previous work (Wang et al. [4]) & This work $^{\mathrm{a}}$ \\
Water & & NA & This work \\
Acid gas & & & NA \\
\hline
\end{tabular}

a: Fitted from acid gas-water-alkanolamine ternary systems data

b: Fitted from acid gas-water binary systems data 
Table 3. BIP values and ARD of liquid compositions ( $\left.x_{\text {acid gas }}\right)$ between PR-CPA EoS results and experimental data for $\mathrm{CO}_{2}$-water binary system.

\begin{tabular}{lcccccc}
\hline System & \multicolumn{7}{c}{$k_{i j}(a+b / T)$} \\
\hline & $\mathrm{T} / \mathrm{K}$ & ARD $x_{\text {acid gas }}$ & $\mathrm{a}$ & $\mathrm{b} \times 10^{3} / \mathrm{K}^{-1}$ & $\beta^{\mathrm{AiBj}}$ & References \\
\hline $\mathrm{H}_{2} \mathrm{~S}$-water & $283-443$ & 2.1 & 0.0998 & $\mathrm{NA}$ & 0.01427 & {$[27,28]$} \\
$\mathrm{CO}_{2}$-water & $278-479$ & 5.4 & 0.0052 & 0.397 & 0.0136 & {$[26,29,30]$} \\
\hline $1 / \mathrm{np} \times \Sigma\left|1-\chi_{i}^{\text {calc }} / \chi_{i}^{\text {exp }}\right| \times 100 \% . \chi:$ solubility of acid gas in water, Np: number of point
\end{tabular}

$\mathrm{ARD} \%=\overline{1 / \mathrm{np} \times \Sigma\left|1-\chi_{i}^{\text {calc }} / \chi_{i}^{\mathrm{exp}}\right| \times 100 \% \cdot \chi: \text { solubility of acid gas in water, } \text { Np: number of point }}$ 
Table 4 BIP values and ARD of total pressure between PR-CPA EoS results and experimental data for acid gas -alkanolamine binary system

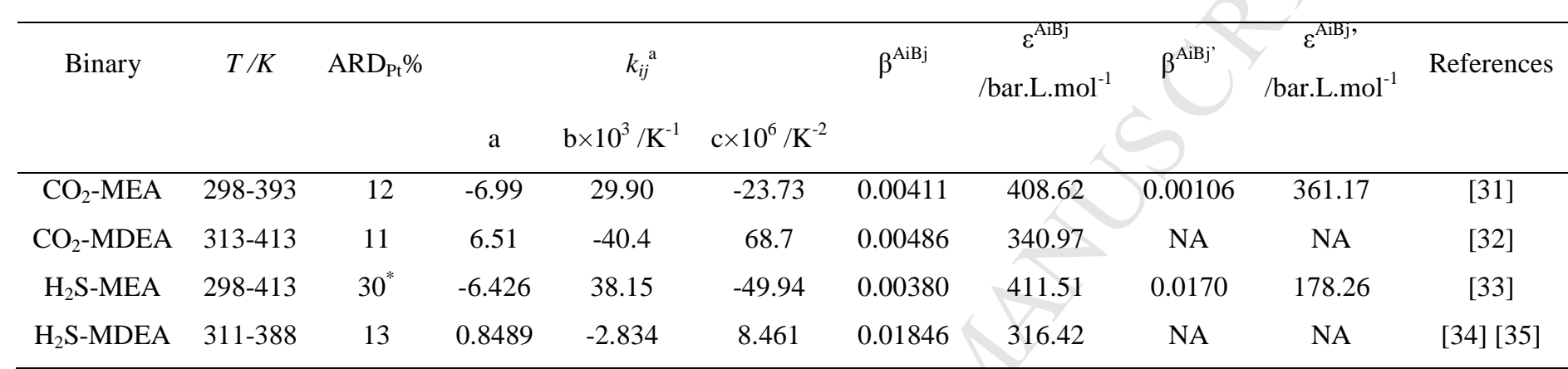

$\mathrm{a}: \mathbf{k i j}=\mathbf{a}+\mathbf{b} \cdot \mathrm{T}+\mathbf{c} \cdot \mathrm{T}^{2}, \mathrm{ARD}_{\mathrm{Pt}} \mathrm{ARD}$ on total pressure of acid gas-water-alkanolamine ternary systems

*: ARD\% on partial pressure of $\mathrm{H}_{2} \mathrm{~S}$ 
Table $5 \mathrm{t}$-Student test results for acid gas mixture in aqueous alkanolamine solution

\begin{tabular}{lcccc}
\hline & \multicolumn{2}{c}{$\mathrm{CO}_{2}$} & \multicolumn{2}{c}{$\mathrm{H}_{2} \mathrm{~S}$} \\
& & & & \\
& $\mathrm{P}$ value & $\mathrm{t}$ & $\mathrm{P}$ value & $\mathrm{t}$ \\
\hline $\mathrm{CO}_{2}-\mathrm{H}_{2} \mathrm{~S}$-water-MEA & 0.033 & 2.183 & 0.001 & 4.444 \\
& & & & \\
$\mathrm{CO}_{2}-\mathrm{H}_{2} \mathrm{~S}$-water-MDEA & 0.057 & 1.920 & 0.073 & 1.806 \\
& & & & \\
\hline
\end{tabular}

*the $\mathrm{P}$ values correspond to the maximum value of $\alpha$ 

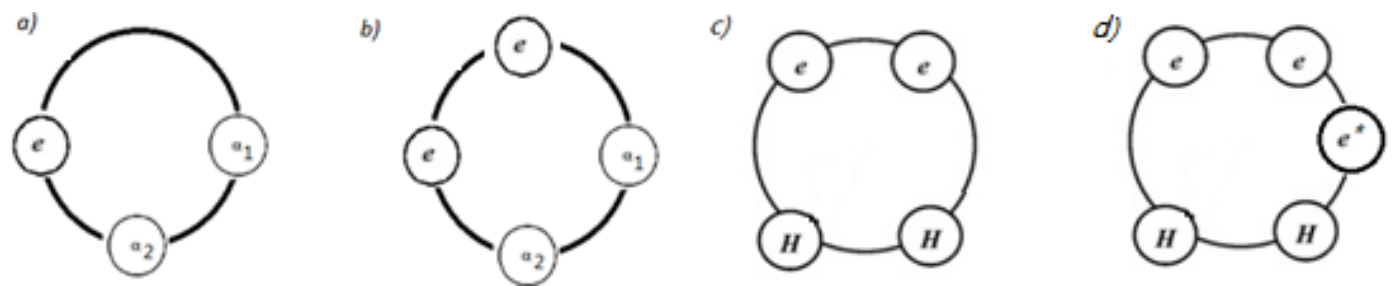

Figure 1 association schemes developed in this research a) $\mathrm{CO}_{2}$, b) $\mathrm{H}_{2} \mathrm{~S}$, c) water and symmetric model for alkanolamine, d) asymmetric model for alkanolamine. 

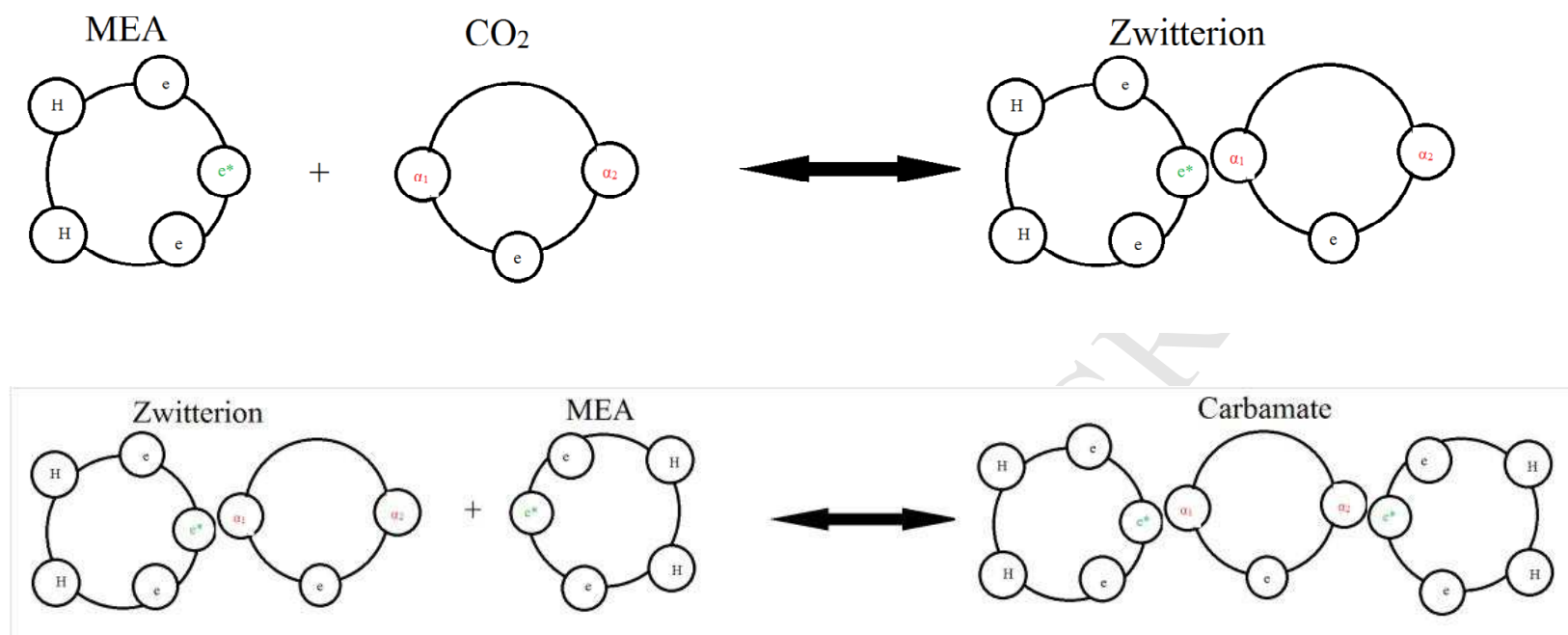

Figure 2 Reaction mechanism between $\mathrm{CO}_{2}$ and MEA (asymmetric model). 


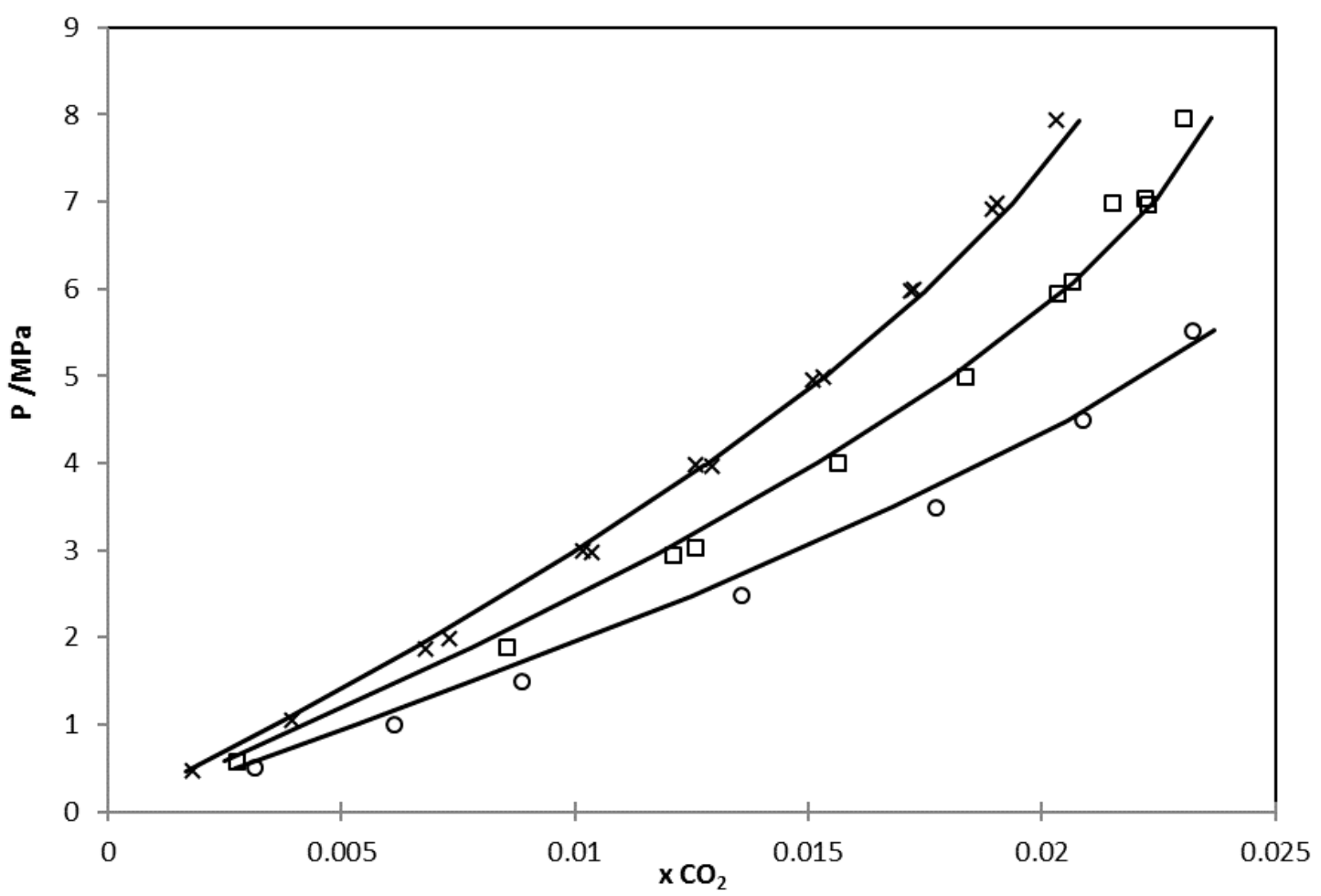

Figure 3 Comparison of experimental $\mathrm{CO}_{2}$ solubility in water and PR-CPA EoS results, solid line: PR-CPA EoS symbols: experimental data from Valtz et al. $[26]$; $(\circ)=298 \mathrm{~K},(\square)=308 \mathrm{~K},(*)=318 \mathrm{~K}$. 


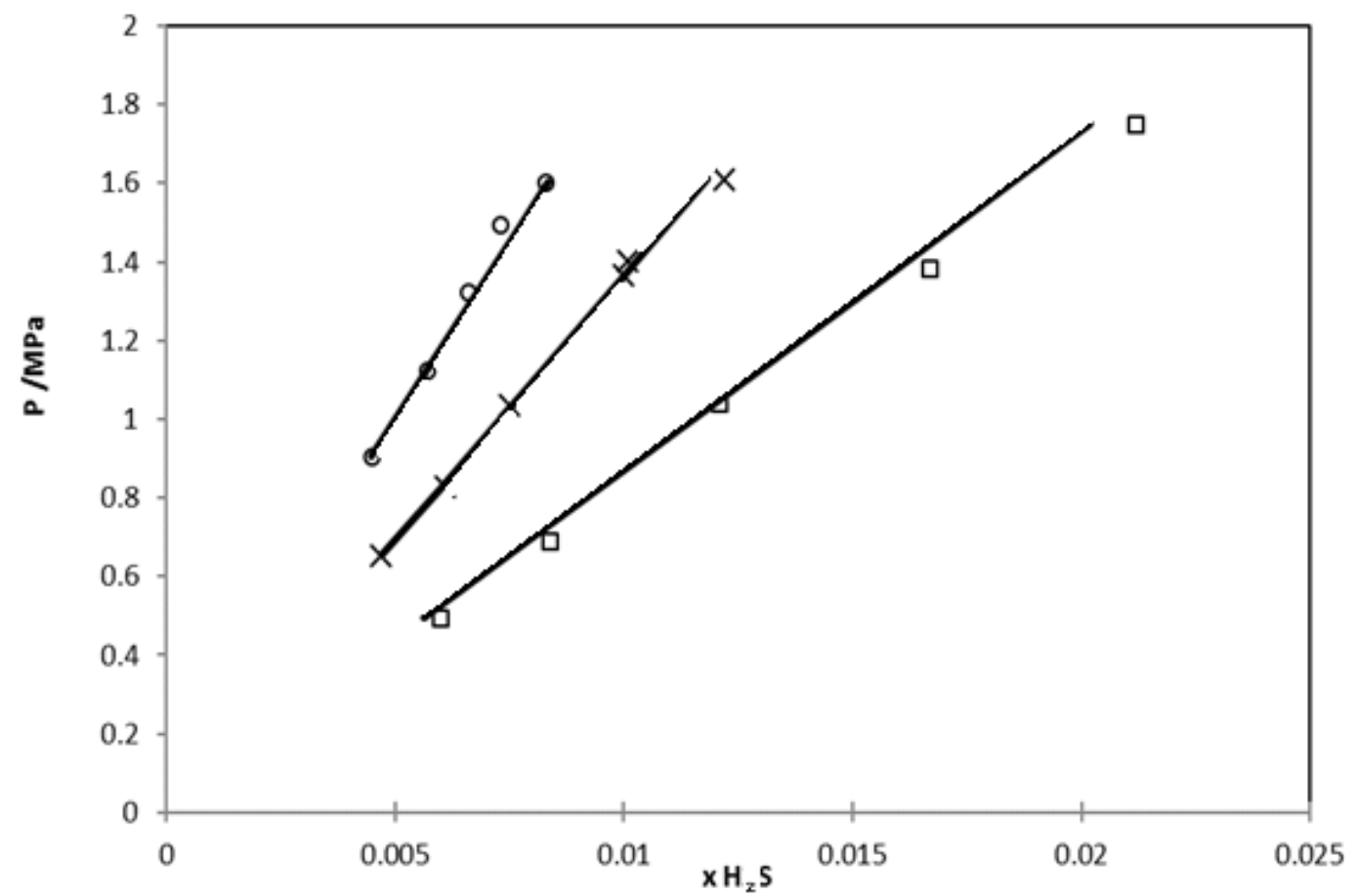

Figure 4 Comparison of experimental $\mathrm{H}_{2} \mathrm{~S}$ solubility in water and PR-CPA results, symbols: experimental data from Selleck et al. [27]; , solid lines: PR-CPA EoS, $(\square)=311 \mathrm{~K}(\mathrm{x})=344 \mathrm{~K},(\circ)=377 \mathrm{~K}$. 


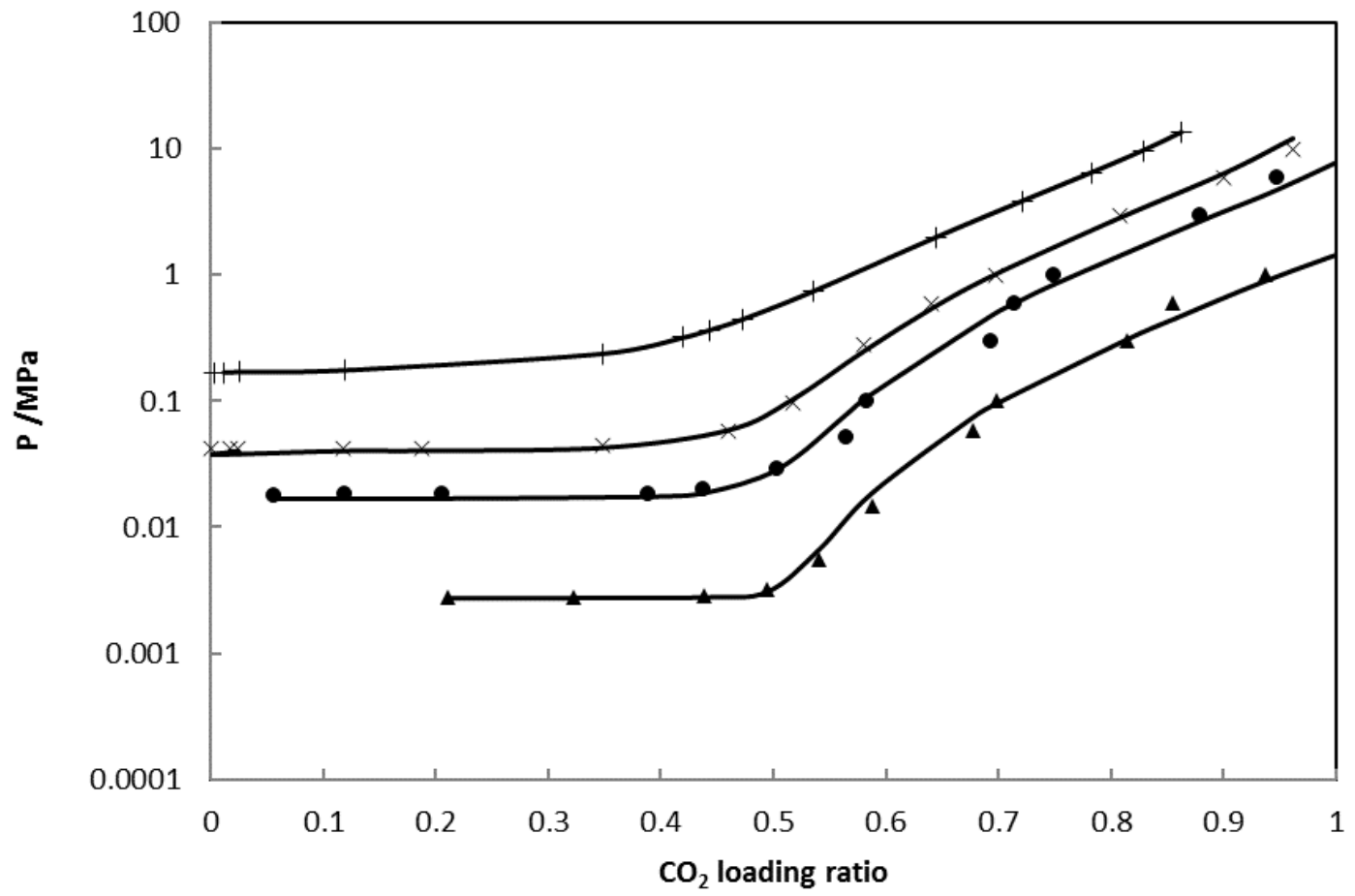

Figure 5 Comparison of experimental total pressure of $\mathrm{CO}_{2}$-MEA-water ternary system with 30 wt $\%$ MEA and PR-CPA results. Solid lines: PR-CPA EoS. Symbols: experimental data from Jou et al. [31]. $(\Delta)=298 \mathrm{~K},(\bullet)=333$

K, $(x)=353 \mathrm{~K},(+)=393 \mathrm{~K}$ 


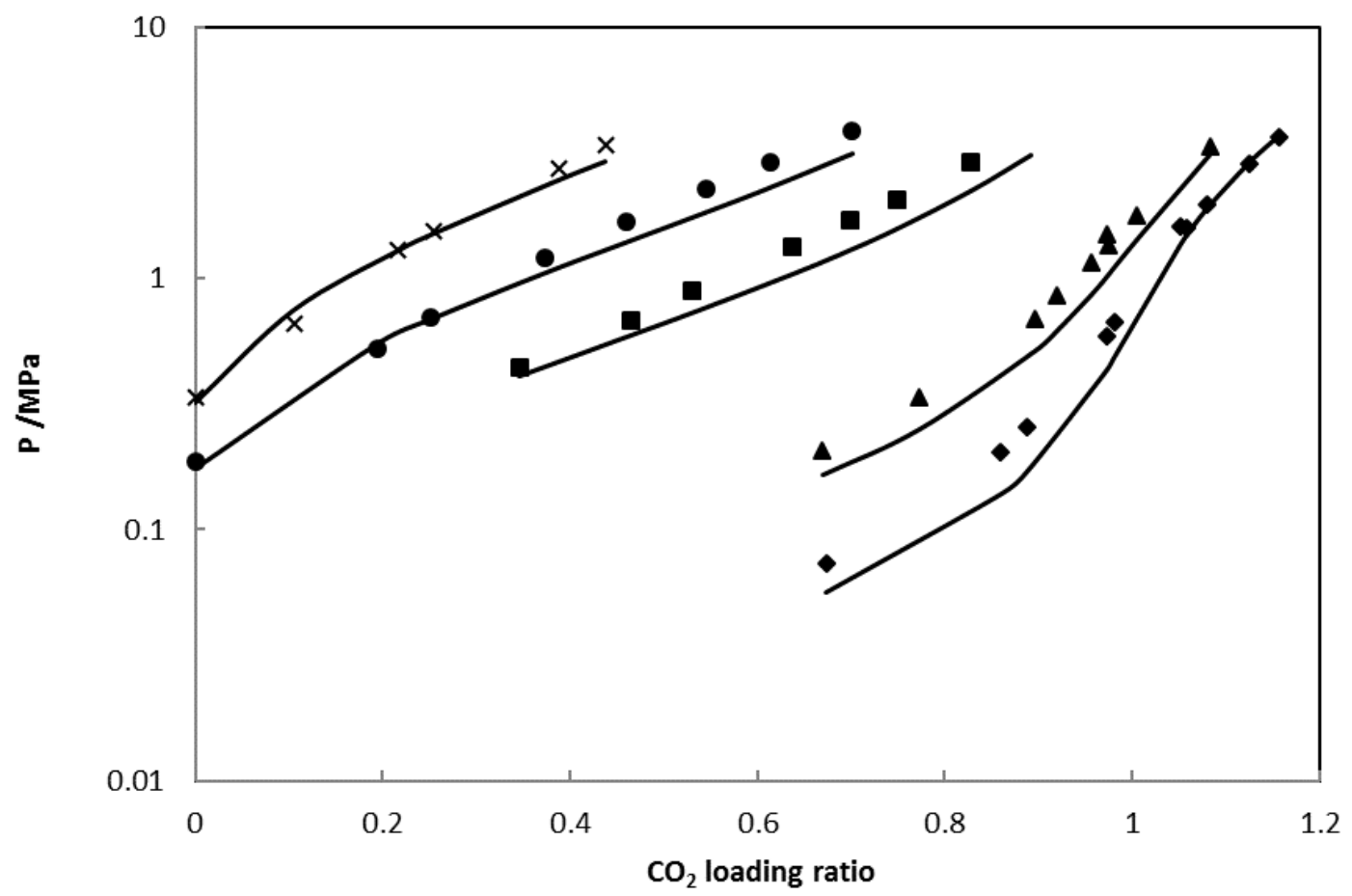

Figure 6 Comparison of experimental total pressure of $\mathrm{CO}_{2}$-MDEA-water ternary system with 32 wt\% MDEA and PR-CPA results. Solid lines: PR-CPA EoS. Symbols: experimental data [32]. $(\diamond)=313 \mathrm{~K},(\triangle)=333 \mathrm{~K}$, $(\bullet)=373 \mathrm{~K},(\bullet)=393 \mathrm{~K},(\times)=413 \mathrm{~K}$. 


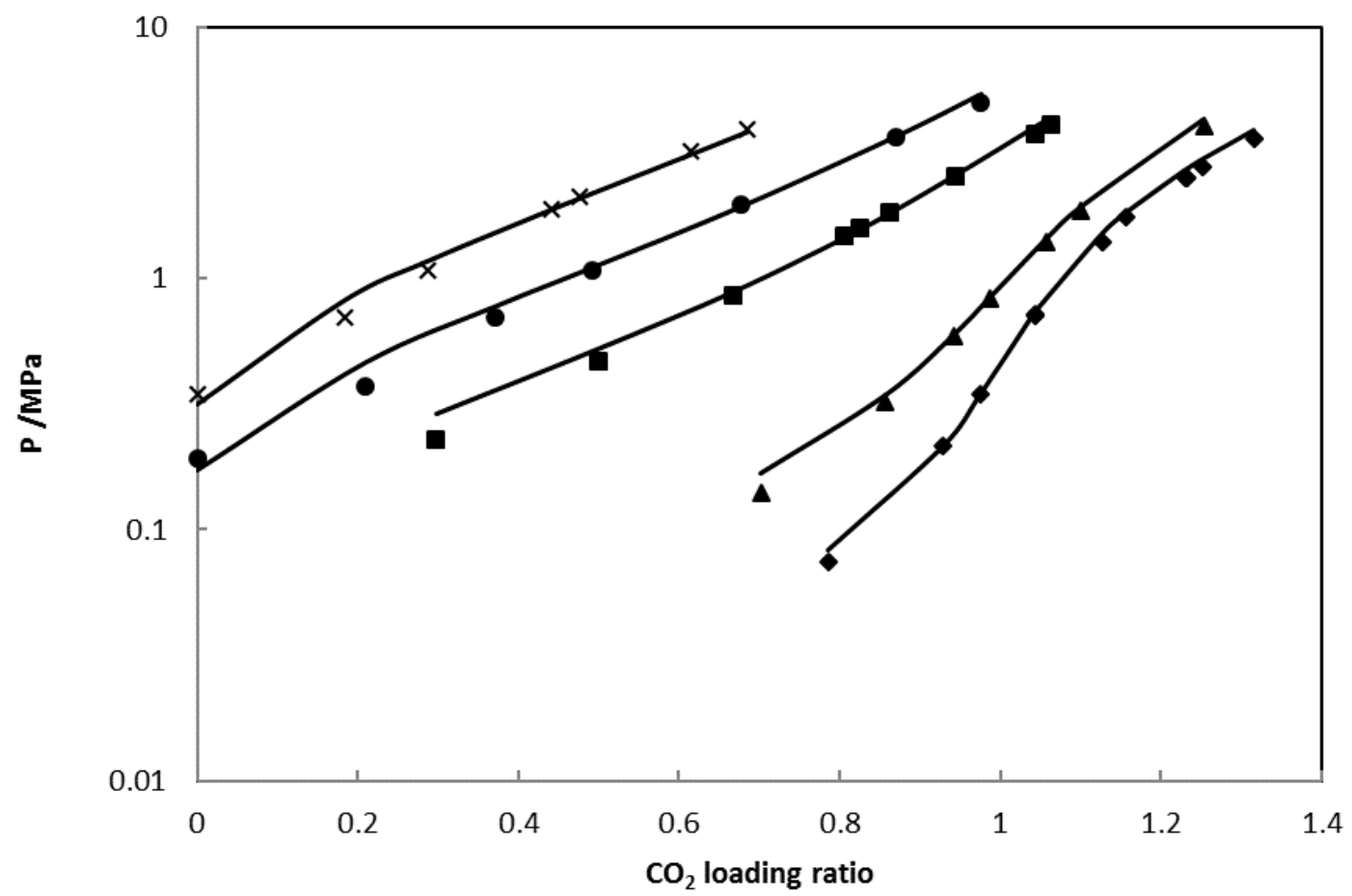

Figure 7 Comparison of experimental total pressure of $\mathrm{CO}_{2}$-MDEA-water ternary system with 19 wt\% MDEA and PR-CPA results. Solid lines: PR-CPA EoS. Symbols: experimental data Kuranov et al. [32]. ( $)=313$ K, $(\Delta)=333 \mathrm{~K},(\bullet)=373 \mathrm{~K},(\bullet)=393 \mathrm{~K},(\times)=413 \mathrm{~K}$ 


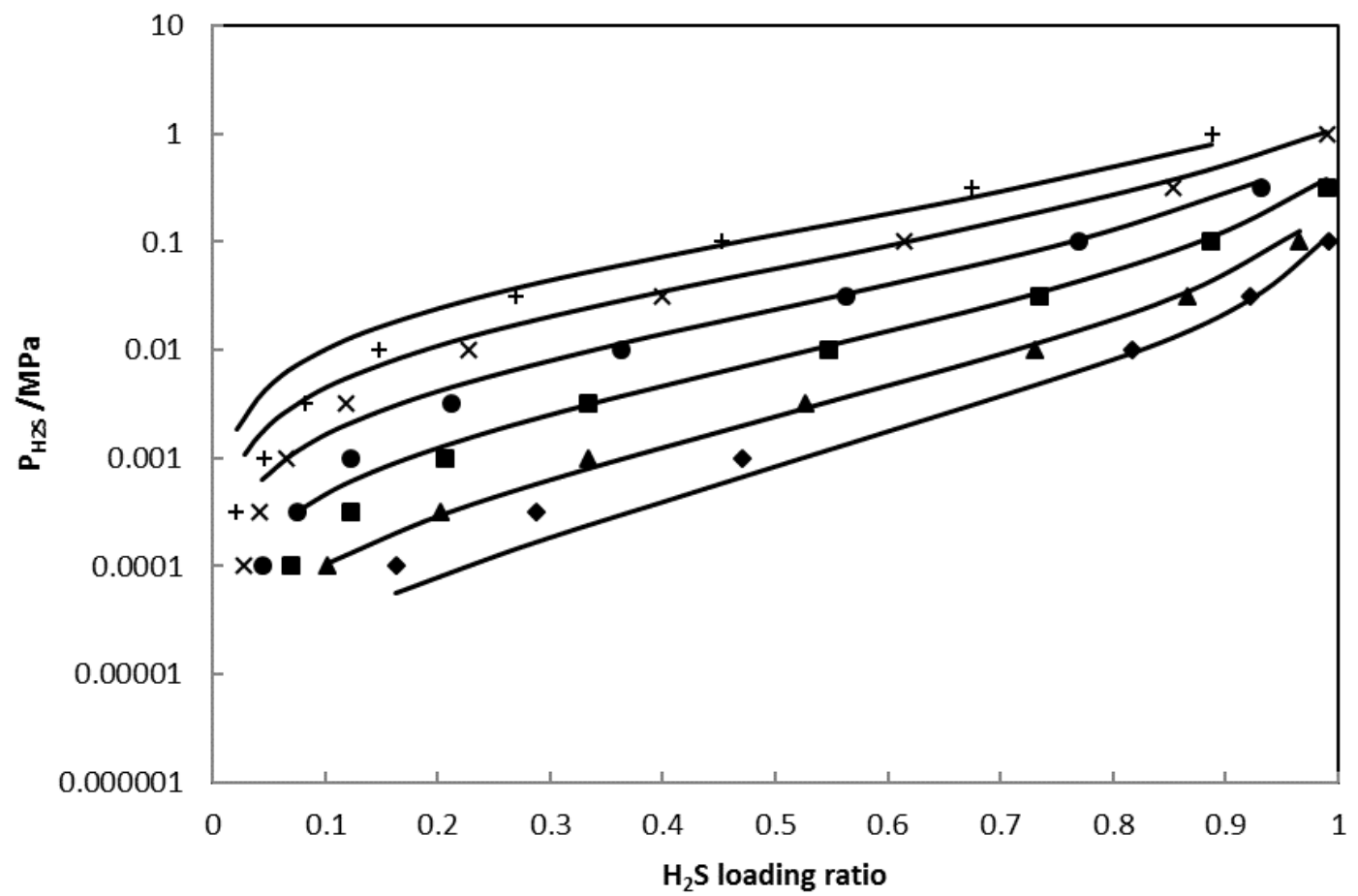

Figure 8 Comparison of experimental $\mathrm{H}_{2} \mathrm{~S}$ partial pressure of $\mathrm{H}_{2} \mathrm{~S}-\mathrm{MEA}$-water ternary system with 30 wt $\%$ MEA and PR-CPA results. Solid lines: PR-CPA EoS, symbols: experimental data from Lee et al. [33]. ( $($) )=298 K, $(\triangle)=313 \mathrm{~K},(\bullet)=333 \mathrm{~K},(\bullet)=353 \mathrm{~K}, \quad(\times)=373 \mathrm{~K},(+)=393 \mathrm{~K}$. 


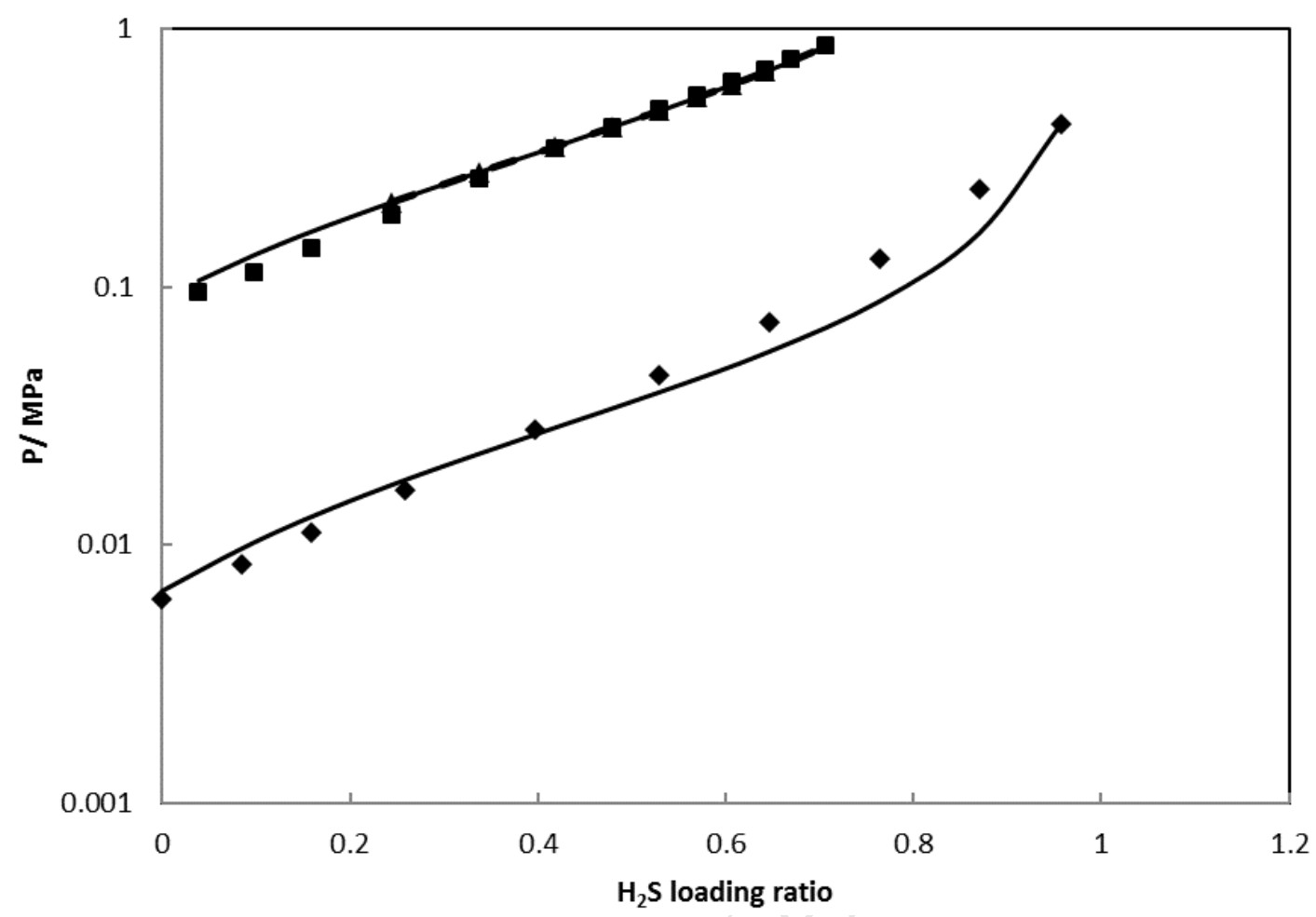

Figure 9 Comparison of experimental total pressure of $\mathrm{H}_{2} \mathrm{~S}$-MDEA-water ternary system with 48 wt\% MDEA and PR-CPA results. Solid lines: PR-CPA EoS. Symbols: experimental data from Sidi-Boumedine et al. [34] . $(\diamond)=313 \mathrm{~K},(\square)=373 \mathrm{~K}$. 


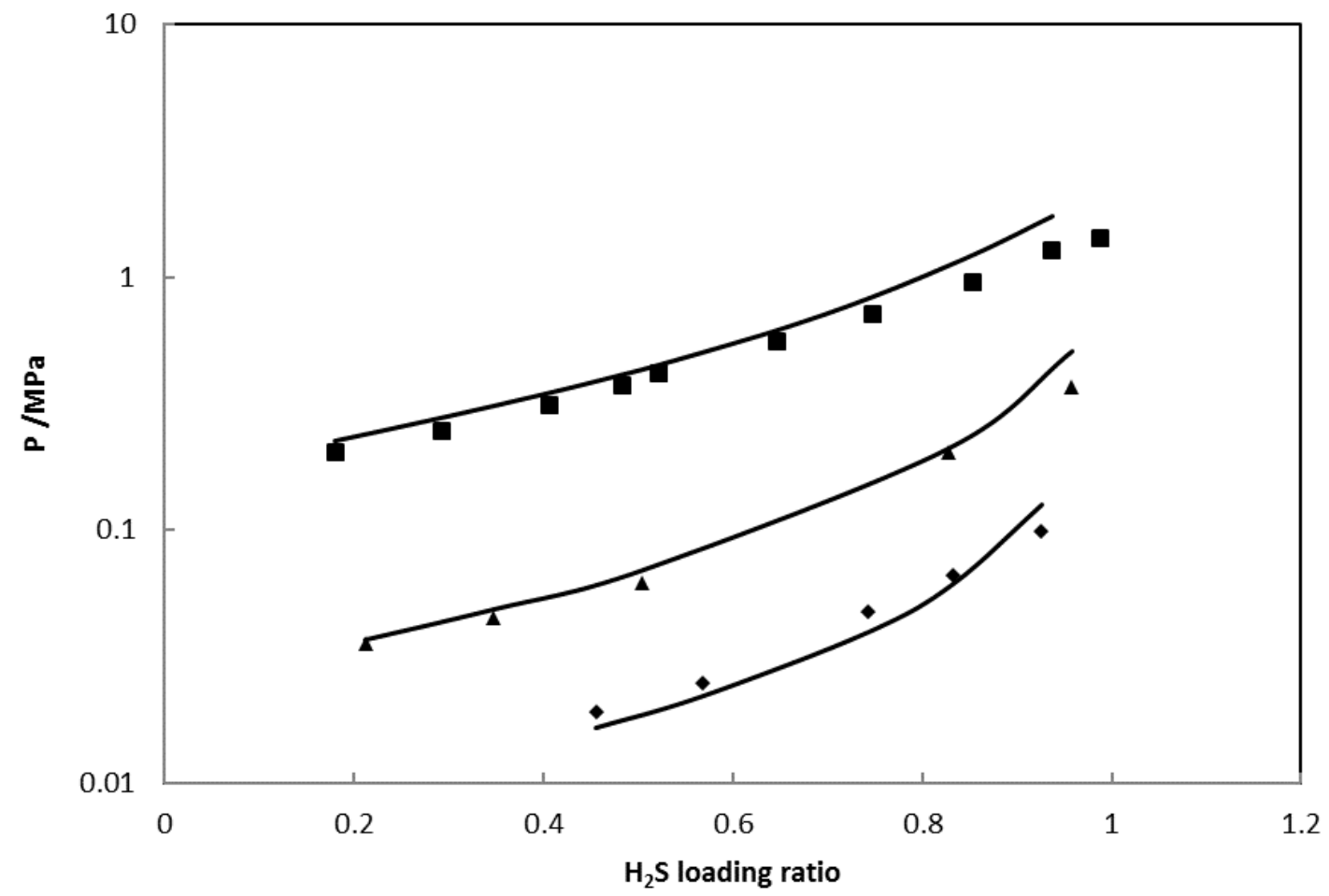

Figure 10 Comparison of experimental total pressure of $\mathrm{H}_{2} \mathrm{~S}-\mathrm{MDEA}$-water ternary system with 20 wt \% MDEA and PR-CPA results. Solid lines: PR-CPA EoS. Symbols: experimental data from Bhairi et al. [35] . ( $\diamond)=311 \mathrm{~K}$, $(\triangle)=338 \mathrm{~K},(\mathbf{\square})=388 \mathrm{~K}$. 


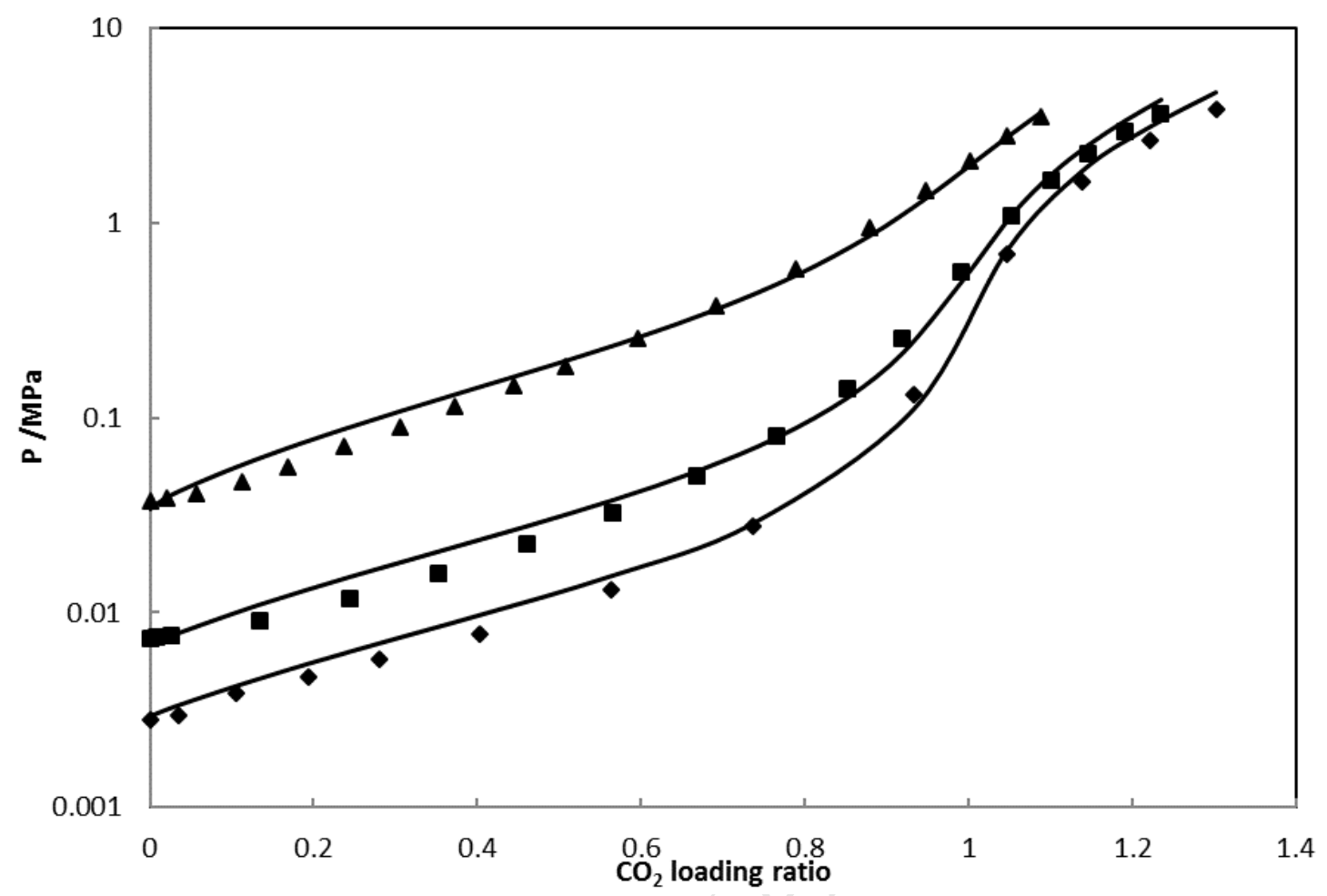

Figure 11 Exploration of total pressure of $\mathrm{CO}_{2}$-MDEA-water ternary system with 25 wt\% MDEA using PRCPA. Solid lines: PR-CPA EoS. Symbols: experimental data from Sidi-Boumedine et al.[34]. $(\diamond)=298 \mathrm{~K}$, $(\Delta)=313 \mathrm{~K},(\boldsymbol{\square})=348 \mathrm{~K}$. 


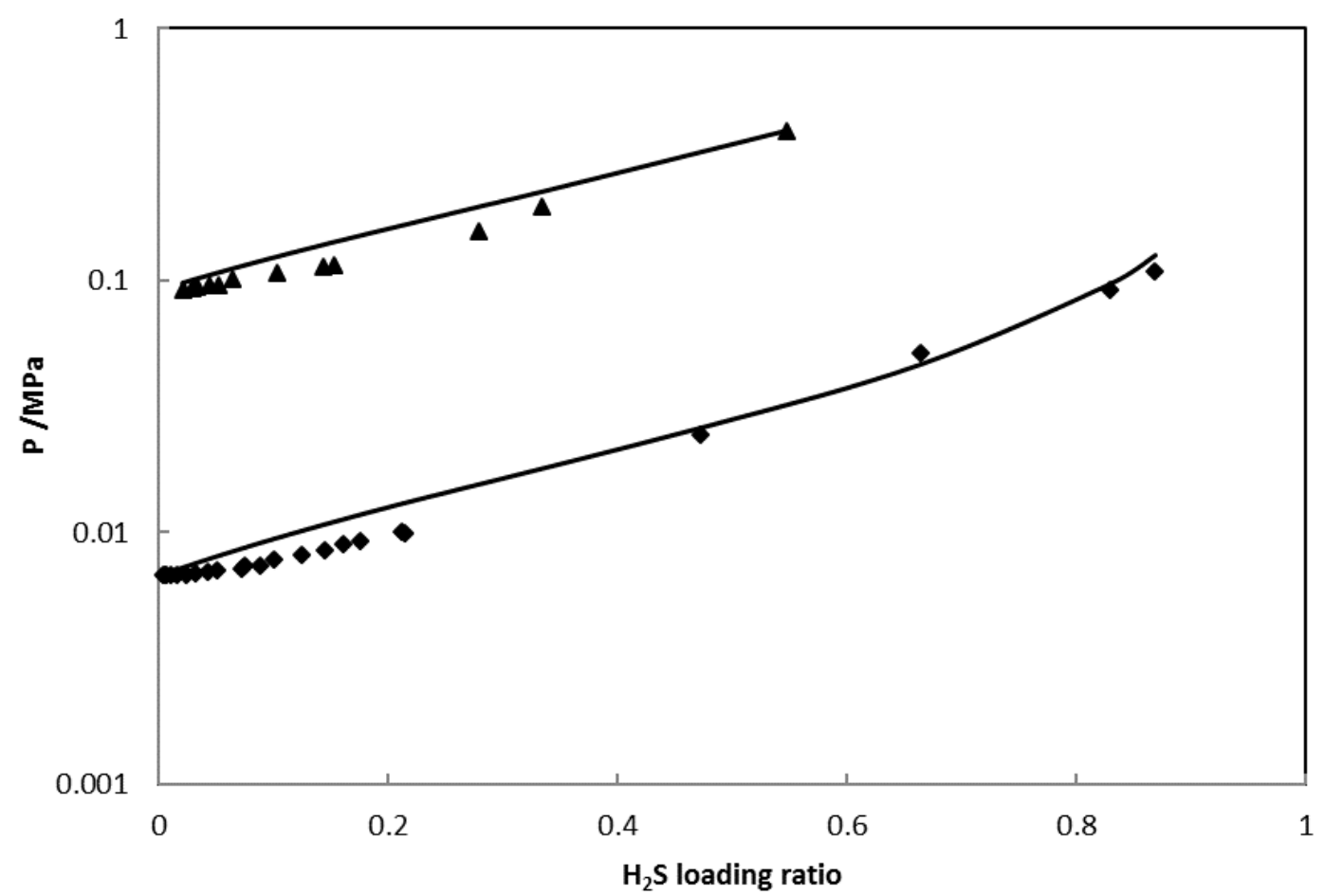

Figure 12 Exploration of total pressure of the $\mathrm{H}_{2} \mathrm{~S}-\mathrm{MDEA}$-water ternary system with 35 wt\% MDEA using PRCPA. Symbols: experimental data from Jou et al. [36] . Solid lines: PR-CPA EoS. $(\diamond)=313$ K, $(\Delta)=373$ K. 


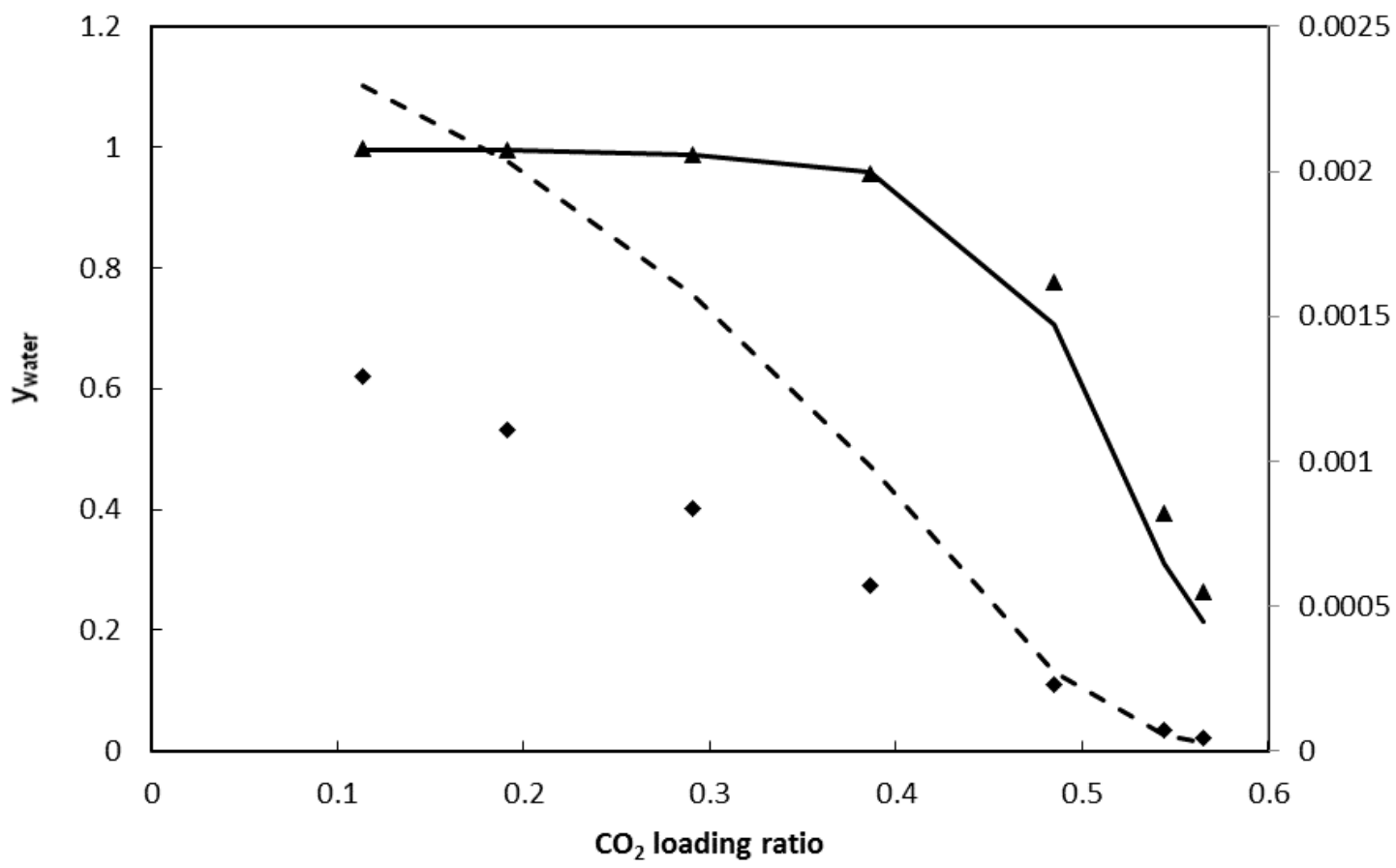

Figure 13 Comparison of vapour phase composition of the $\mathrm{CO}_{2}$-MEA-water ternary system with 30 wt \% MEA

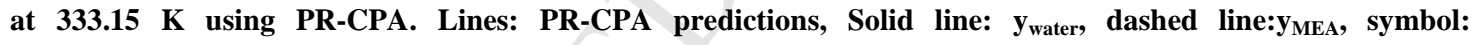
experimental data from Hilliard et al. [37] $(\Delta)=\mathbf{y}_{\text {water }}(\diamond)=\mathbf{y}_{\text {MEA }}$. 


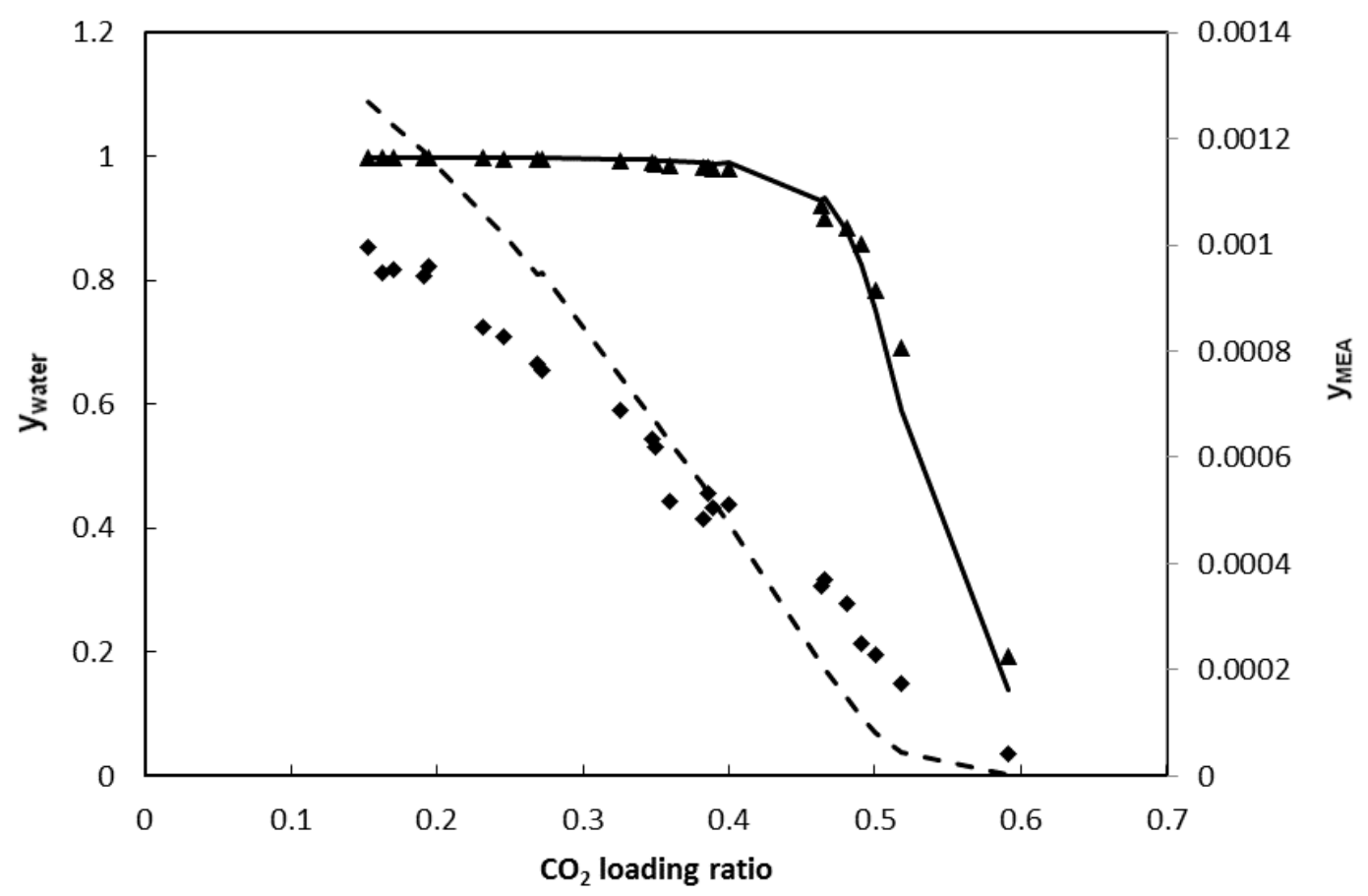

Figure 14 Comparaison of vapour phase composition of $\mathrm{CO}_{2}$-MEA-water ternary system with 30 wt \% MEA at 313.15 K using PR-CPA. Lines: PR-CPA predictions, Solid line: $y_{\text {water }}$, dashed line: $\mathbf{y}_{\text {MEA }}$, symbol: experimental data from Hilliard et al. [37] $(\Delta)=\mathbf{y}_{\text {water }},(\diamond)=\mathbf{y}_{\text {MEA }}$ 


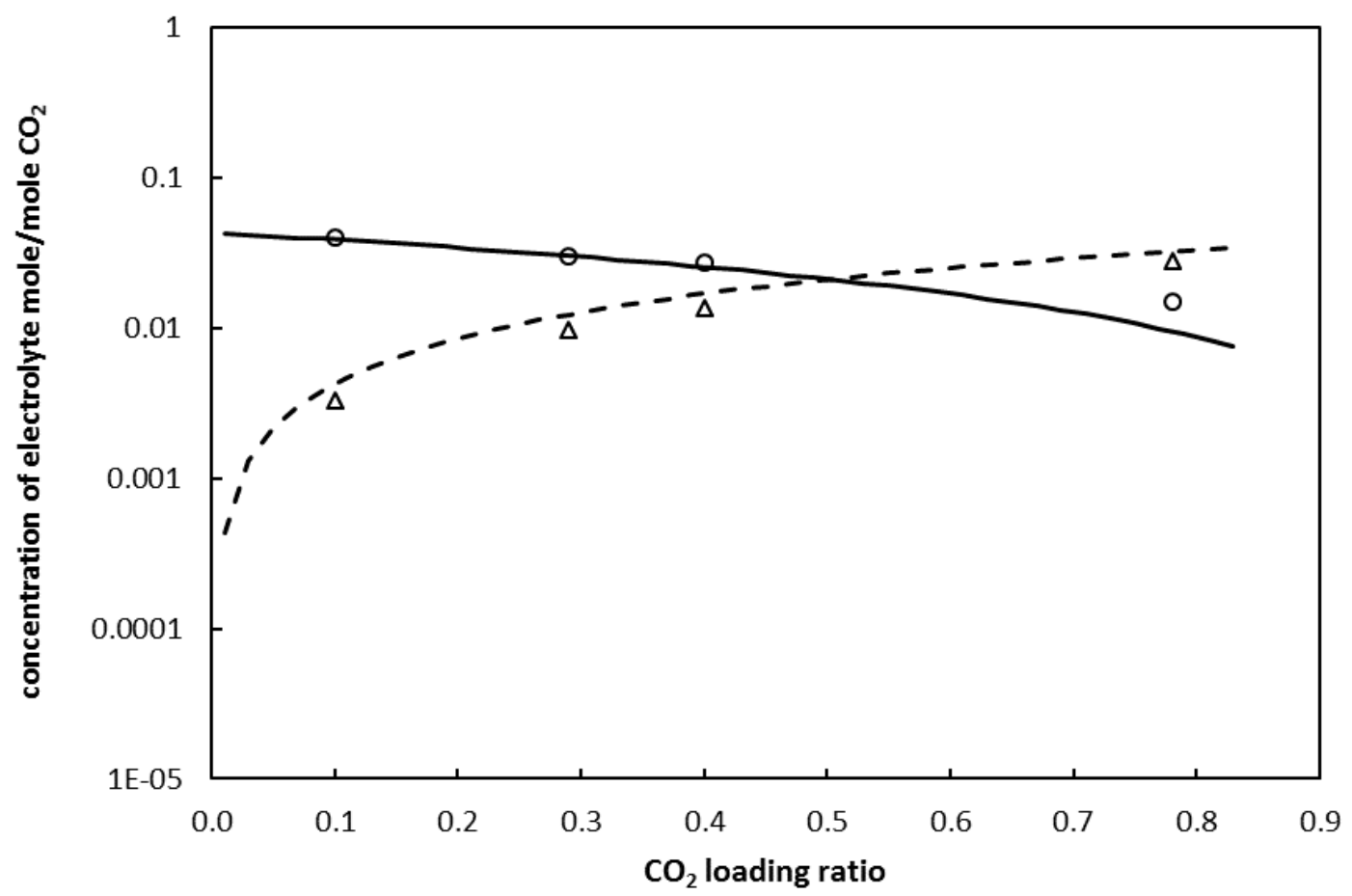

Figure 15 Prediction of liquid phase electrolyte speciation of $\mathrm{CO}_{2}$-MDEA-water ternary system with 30 wt \% MDEA at 313K using PR-CPA. Solid line: MDEA, dotted line: $\mathrm{HCO}_{3}{ }^{-1}$ symbols: experimental data from Jakobsen et al. [38]: $(\Delta)=\mathrm{HCO}_{3}^{-1},(\circ)=$ MDEA. 


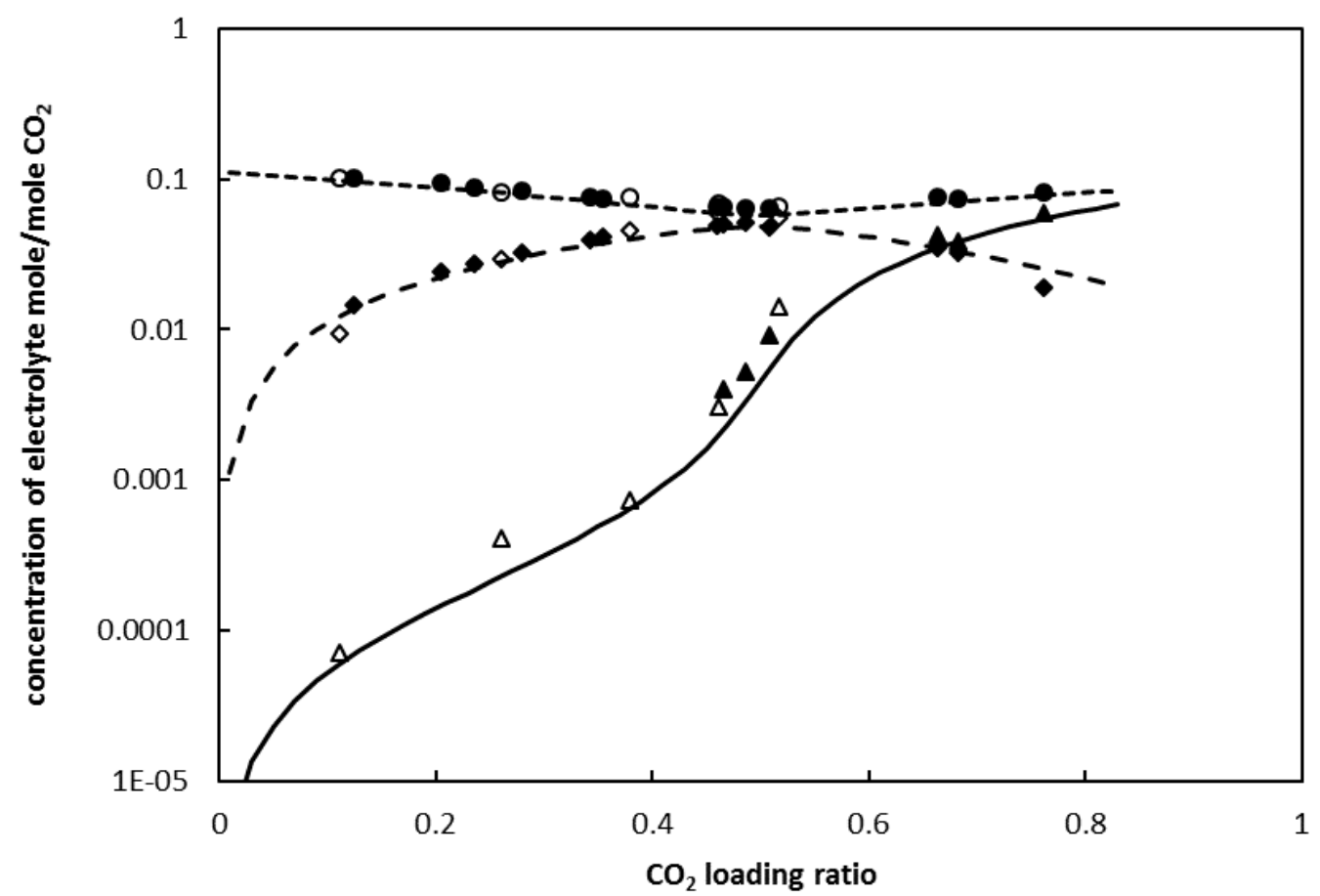

Figure 16 Prediction of liquid phase electrolyte speciation of $\mathrm{CO}_{2}$-MEA-water ternary system with 30 wt \% MEA at 313.15 K using PR-CPA. Solid line: $\mathrm{HCO}_{3}^{-1}$, dashed line: $\mathrm{MEACOO}{ }^{-}$, dotted line: MEA+MEAH', symbols: experimental data from Hilliard et al. [39] $(\Delta)=\mathrm{HCO}_{3}^{-1},(\diamond)=\mathrm{MEACOO}^{-}(\circ)=\mathrm{MEA}^{-\mathrm{MEAH}^{+}}$from $^{-}$ Hilliard [37], $(\Delta)=\mathrm{HCO}_{3}^{-1},(\diamond)=\mathrm{MEACOO}_{-}(\bullet)=\mathrm{MEA}+\mathrm{MEAH}^{+}$. 


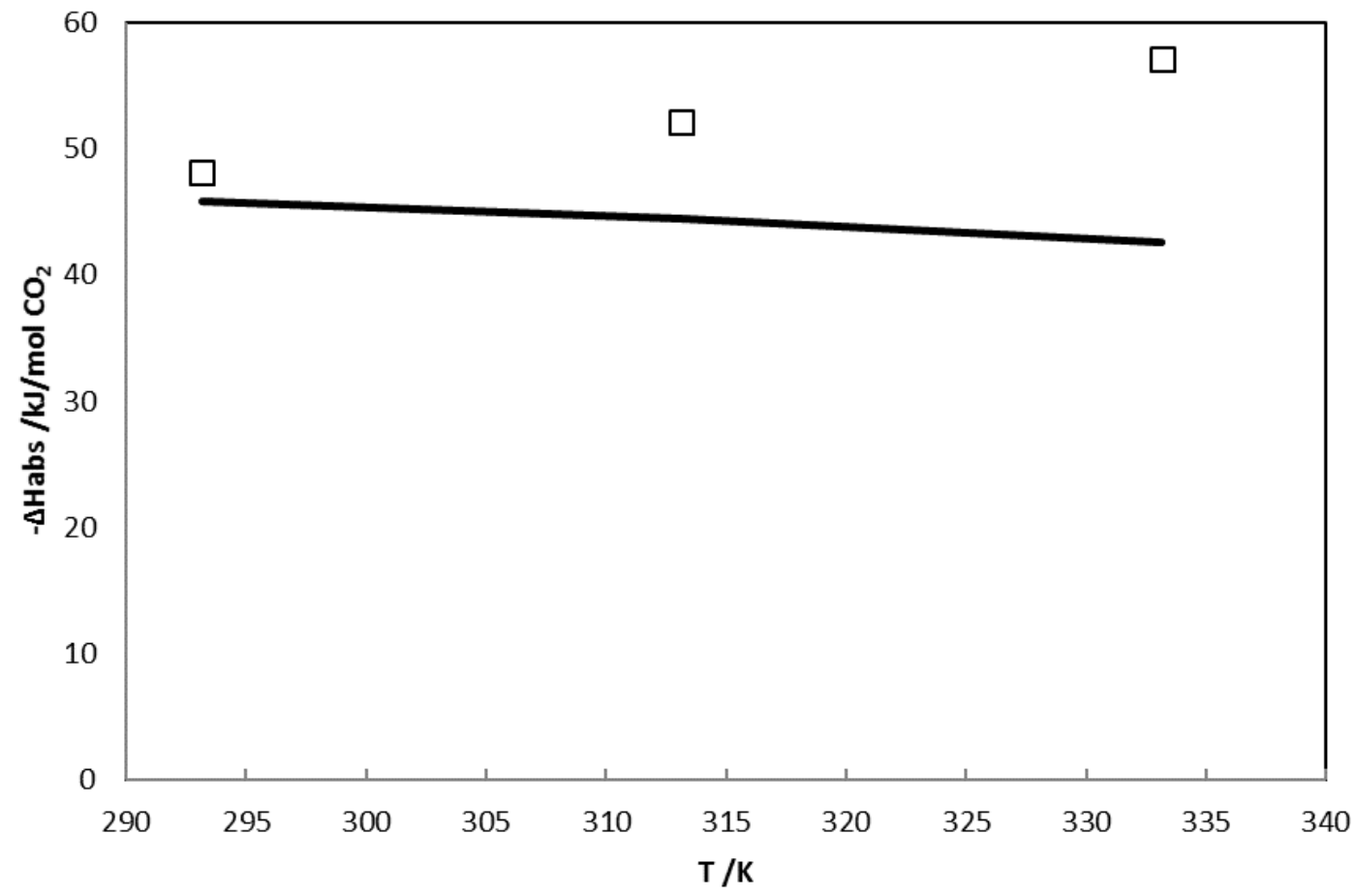

Figure 17 Prediction of enthalpy of absorption of $\mathrm{CO}_{2}$-MDEA-water ternary system with 20 wt \% MDEA loading ratio of 0.5 using PR-CPA EoS. Lines: PR-CPA EoS prediction, symbols: experimental data from Gupta et al. [41] 


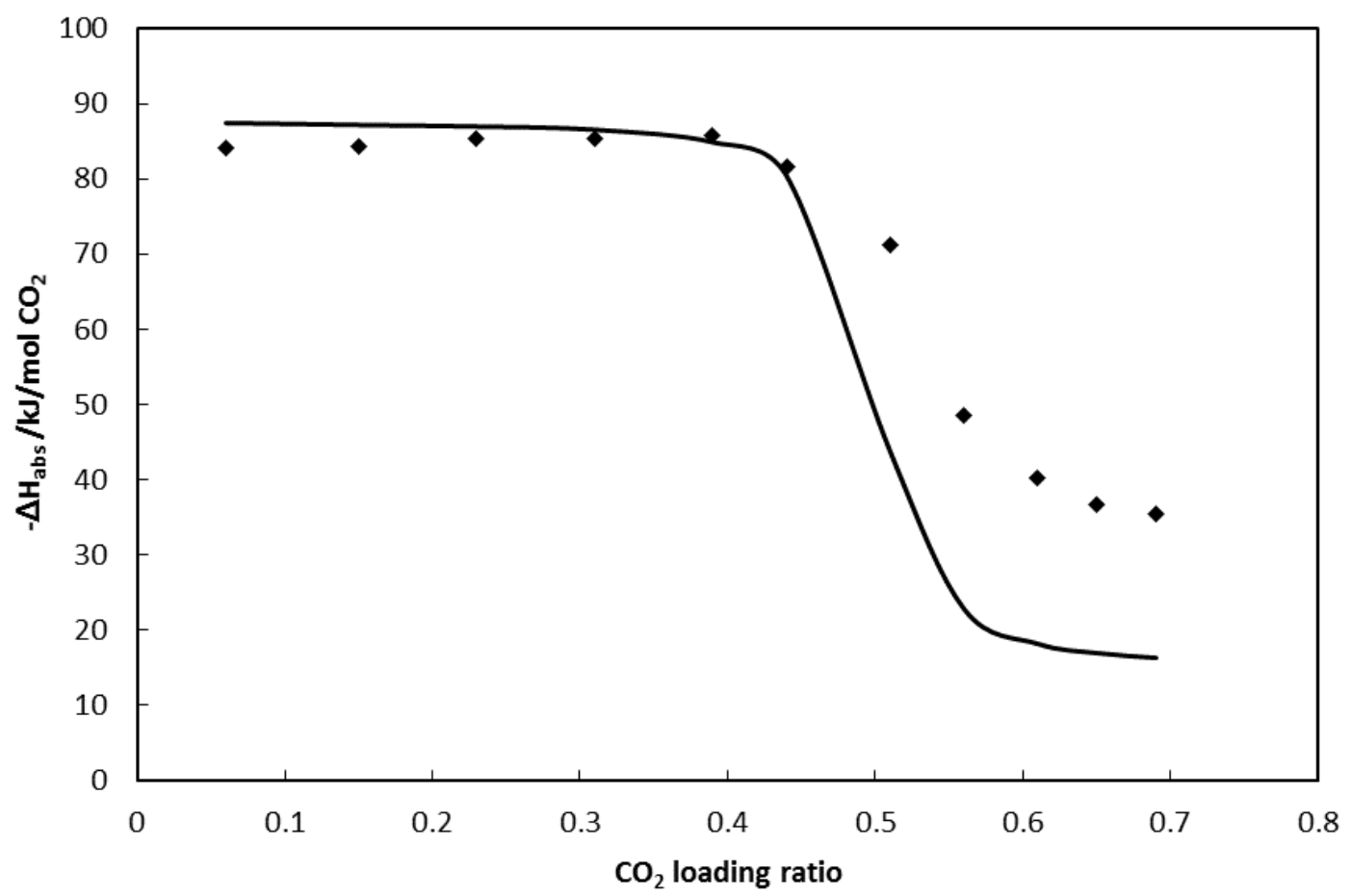

Figure 18 Prediction of enthalpy of absorption of $\mathrm{CO}_{2}$-MEA-water ternary system with $30 \mathrm{wt} \%$ MEA at 313.15 K using PR-CPA. Solid line PR-CPA EoS, symbol: experimental data from Hilliard et al. [37] 


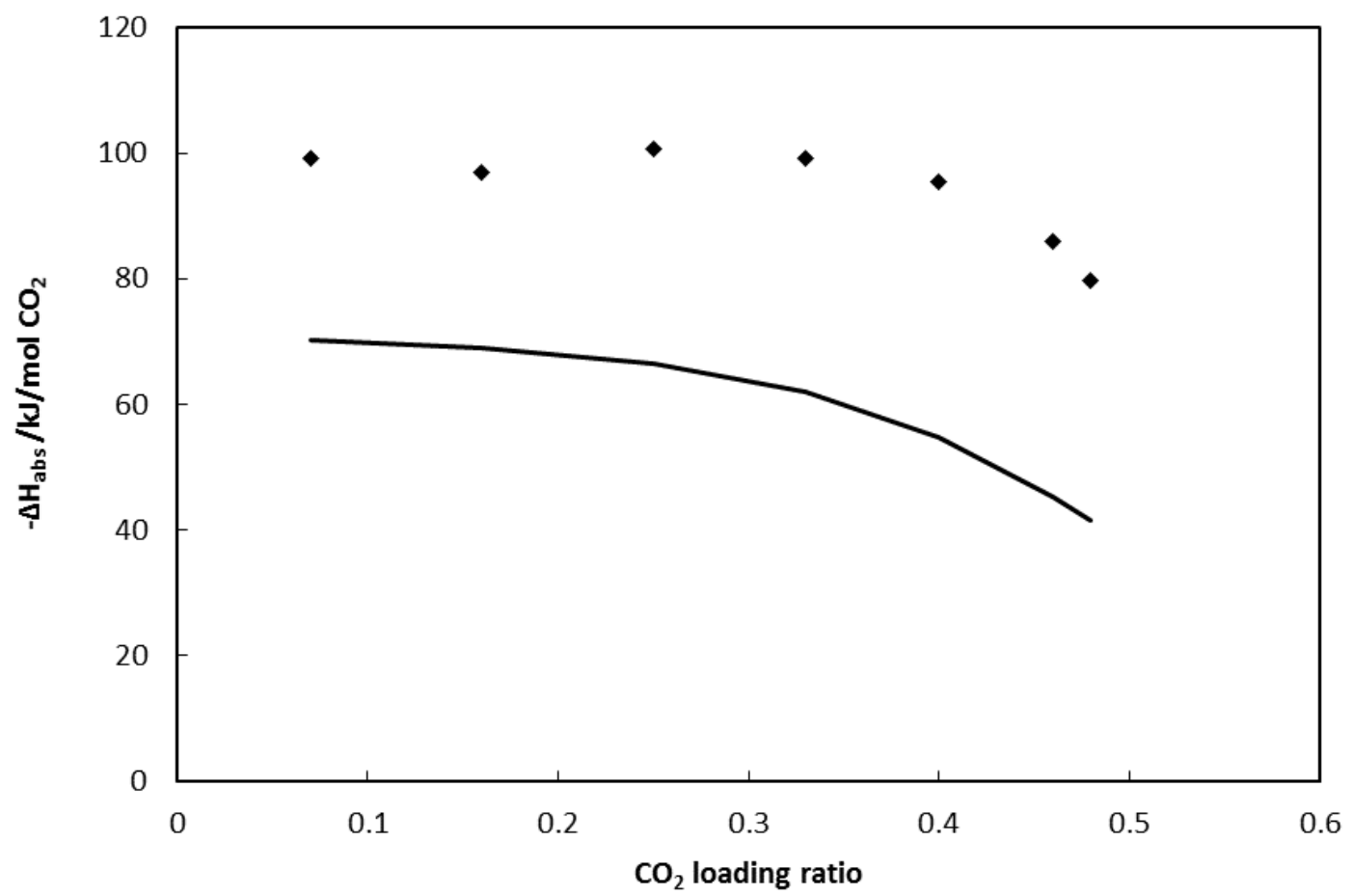

Figure 19 Prediction of enthalpy of absorption of $\mathrm{CO}_{2}$-MEA-water ternary system with $30 \mathrm{wt} \%$ MEA at 393.15 K using PR-CPA. Solid line: PR-CPA EoS, symbols: experimental data from Hilliard et al. [37]. 